\title{
Melanoma plasticity and phenotypic diversity: therapeutic barriers and opportunities
}

\author{
Florian Rambow, ${ }^{1,2}$ Jean-Christophe Marine, ${ }^{1,2}$ and Colin R. Goding ${ }^{3}$ \\ ${ }^{1}$ Laboratory for Molecular Cancer Biology, Center for Cancer Biology, Vlaams Instituut voor Biotechnologie (VIB), Herestraat 49, \\ 3000 Leuven, Belgium; ${ }^{2}$ Laboratory for Molecular Cancer Biology, Department of Oncology, KULeuven, Herestraat 49, B-3000 \\ Leuven, Belgium; ${ }^{3}$ Ludwig Institute for Cancer Research, Nuffield Department of Clinical Medicine, University of Oxford, \\ Headington, Oxford OX3 7DQ, United Kingdom
}

\begin{abstract}
An incomplete view of the mechanisms that drive metastasis, the primary cause of cancer-related death, has been a major barrier to development of effective therapeutics and prognostic diagnostics. Increasing evidence indicates that the interplay between microenvironment, genetic lesions, and cellular plasticity drives the metastatic cascade and resistance to therapies. Here, using melanoma as a model, we outline the diversity and trajectories of cell states during metastatic dissemination and therapy exposure, and highlight how understanding the magnitude and dynamics of nongenetic reprogramming in space and time at single-cell resolution can be exploited to develop therapeutic strategies that capitalize on nongenetic tumor evolution.
\end{abstract}

Genetic vs. nongenetic intratumor heterogeneity

The metastatic dissemination of cancer cells to secondary sites and their growth in vital organs is a major determinant of cancer patients' morbidity and mortality. Although improved surgery and radiotherapy coupled with the advent of newer immunotherapeutic and molecularly targeted agents have led to a substantial increase in metastatic cancer patient survival (Nowell 1976; Scott et al. 2012; Sottoriva et al. 2013), treating metastatic disease remains a key challenge for oncologists. The clinical benefit associated with current therapies is limited by the almost inevitable development of resistance and tumor recurrence. Although, the molecular events underpinning metastatic dissemination and therapy resistance are complex, recent findings have highlighted that two common and interrelated mechanisms operate.

The first and most commonly accepted molecular explanation for both metastatic dissemination and the al-

[Keywords: MITF; phenotypic plasticity; melanoma; microenvironment; cancer]

Corresponding authors: colin.goding@ludwig.ox.ac.uk, jeanchristophe. marine@kuleuven.vib.be

Article is online at http://www.genesdev.org/cgi/doi/10.1101/gad.329771. 119. most inevitable emergence of therapy resistance and tumor recurrence invokes genetic intratumor heterogeneity (ITH) (Nowell 1976; Yachida et al. 2010; Sottoriva et al. 2013; Jamal-Hanjani et al. 2015; Pogrebniak and Curtis 2018). Genetic ITH may arise as a consequence of, among others, replication errors, UV-induced mutagenesis, inefficient DNA damage repair, telomere attrition, or chromosome segregation defects (Jeggo et al. 2016). High ITH is associated with poor prognosis in head and neck cancer (Mroz and Rocco 2013), lung cancer (Zhang et al. 2014), ovarian cancer (Schwarz et al. 2015), and in pan-cancer analyses (Andor et al. 2016). High genetic ITH implies that the tumor is more likely to harbor rare pre-existing subclones, some of which may be endowed with an ability to metastasize or exhibit therapy resistance (Turajlic et al. 2019). For instance, therapies that target driver mutations have been associated with resistance and recurrence in chronic myeloid leukemia (Gerlinger and Swanton 2010) and multiple myeloma (Lohr et al. 2014). Treatments targeting subclonal copy number gains (vs. clonal high-level gains) yielded suboptimal clinical benefit in gastric cancer patients treated with a FGF receptor inhibitor (Pearson et al. 2016). Note that while genetic diversity within a population may confer some cells with a growth or survival advantage when exposed to a specific stress signal, the same genetic variants may exhibit a selective disadvantage when faced with a different challenge (McGranahan and Swanton 2015). Increasing evidence suggests that, while important, genetic ITH appears insufficient to explain the emergence of therapy resistance and the biology of cancer progression, including the process of metastatic dissemination (Pisco and Huang 2015; Pogrebniak and Curtis 2018).

The second mechanism, which is gaining recognition, relies on an intrinsic plasticity in the cancer genome

(C) 2019 Rambow et al. This article is distributed exclusively by Cold Spring Harbor Laboratory Press for the first six months after the full-issue publication date (see http://genesdev.cshlp.org/site/misc/terms.xhtml). After six months, it is available under a Creative Commons License (Attribution-NonCommercial 4.0 International), as described at http://creativecommons.org/licenses/by-nc/4.0/. 
that allows cells to engage adaptive responses to a changing intra-tumor microenvironment that leads to a fundamental change in the biological properties of the cell (Brabletz et al. 2005; Gupta et al. 2009a, 2011; Hoek and Goding 2010; Chaffer et al. 2011; Ocana et al. 2012; Tsai et al. 2012; Huang et al. 2013; Quail and Joyce 2013; Chaffer et al. 2016; Nieto et al. 2016; García-Jiménez and Goding 2019). In contrast to irreversible genetic variation, phenotypic plasticity, in which the epigenetic landscape of a cell has the potential to be remodeled, endows each cell with the potential to adapt its gene expression repertoire in response to perceived changes in the microenvironment in a reversible fashion. Equally important is that adaptation can be graded (Giorgetti et al. 2010). In response to moderate stress exposure, short-term and relatively subtle alterations in gene expression programs driven by signaling-mediated alterations in transcription factor activity may be directed toward maintaining a specific phenotype, for example, by increasing import of a specific nutrient that has become limiting. In contrast, a sustained and/or acute stress situation may require a more profound adaptation leading to widespread and radical alterations in gene expression and, ultimately, a switch into a distinct cellular state that may become stabilized as a consequence of positive feedback loops (Brandman and Meyer 2008) and epigenetic remodeling (Flavahan et al. 2017). In this respect, the phenotypic plasticity encoded by the cancer genome reflects that during development where the specification of multiple cell types with specialized functions requires the epigenetic landscape to be shaped by transcription factors and their associated chromatin remodeling factors (Reiter et al. 2017). Transcription factor activity is regulated by specific signals that may affect their mRNA expression and translation, their subcellular localization and interaction with cofactors, mRNA and protein stability, and target specificity (Calkhoven and Ab 1996; Westermarck 2010; Filtz et al. 2014; Lu et al. 2016). Notably, many of the epigenetic regulators that act as transcription cofactors use metabolic intermediates as cofactors (van der Knaap and Verrijzer 2016), and the coordination of metabolism and gene expression is a critical determinant of tumor behavior (Lehuédé et al. 2016; García-Jiménez and Goding 2019).

Although most, if not all, cancer cells within a given tumor will share the same driver mutations that provide a selective growth advantage, the tumor microenvironment (TME) directs cells into a range of phenotypic states that may coexist in varying proportions (Quail and Joyce 2013). Some cells may be differentiated and reflect the specialized function of the cell of origin. A proportion of cells will be actively cycling and thus fuel tumor growth. A third class of cells will be invasive, some of which may have the potential to seed new metastases. Finally, dormant cells may lie quiescent for many years before their reactivation when they may initiate a new tumor (i.e., metastatic lesion) or give rise to relapse after an apparently successful therapy (Giancotti 2013; Sosa et al. 2014). Unlike physiological cells where the trajectory from a stem cell to a differentiated cell tends to be unidirectional, in cancer, transitions between different phenotypic states appear to be more dynamic and are potentially reversible (Joyce and Pollard 2009; Quail and Joyce 2013; Nieto et al. 2016; Dongre and Weinberg 2019). Although the probability of a cell switching phenotype in response to external cues is likely to be stochastic, to account for more dynamic nature of cancer-associated phenotype switches it has been proposed that the genetic lesions associated with cancer increase the probability of a phenotype switch occurring (García-Jiménez and Goding 2019; Bernards and Weinberg 2002), a phenomenon known as phenotypic instability (Hoek and Goding 2010). Indeed, dynamic and reversible stochastic phenotypic transitions have been observed in breast cancer cell lines even in the absence of an external trigger (Gupta et al. 2011). In other words, and as suggested previously, oncogenic mutations may promote cancer progression (Bernards and Weinberg 2002) by lowering the threshold above which a phenotypic transition may occur (Hoek and Goding 2010).

Importantly, the adaptive responses that can occur upon exposure to a stressful microenvironment are also observed upon therapy and are associated with increased resistance to treatment. For instance, whereas the vast majority of a cultured nonsmall cell lung cancer population was killed upon exposure to therapy, a rapid and transient accumulation of viable/residual "drug-tolerant" cells was observed with a kinetic and frequency that cannot be explained by mutational mechanisms (Sharma et al. 2010; Gupta et al. 2011). Note that, as opposed to drug resistance, drug-tolerance relates to a state in which tumor cells can survive, but not proliferate during treatment (Chisholm et al. 2015). Similar protective responses to treatment were later reported in cultures originating from other types of cancer and in response to a multitude of therapeutic challenges (Pisco et al. 2013; Menon et al. 2015; Pisco and Huang 2015; Seguin et al. 2015). Chemotherapy induces a switch in various epithelial cancers (carcinomas) (Dallas et al. 2009; Polyak and Weinberg 2009; Singh and Settleman 2010) such as colon (Dallas et al. 2009) and gastric (Xue et al. 2012), known as an epithelial-to-mesenchymal transition (EMT), an event associated with chemo-resistance as well as invasiveness (Nieto et al. 2016; Dongre and Weinberg 2019). In nonsmall cell lung cancer treated with anti-PD1 checkpoint inhibitors upregulation of alternative immune checkpoint leads to resistance (Koyama et al. 2016). Moreover, in a mouse model, melanoma resistance to adoptive T-cell therapy can be imposed as a consequence of TNFa derived from infiltrating immune cells driving dedifferentiation (Landsberg et al. 2012). Consistent with this, a metastatic melanoma lesion from a patient undergoing adoptive T-cell transfer therapy acquired resistance to the treatment by undergoing dedifferentiation caused by a down-regulation of melanocytic antigens and acquisition of the neural crest stem cell (NCSC) marker nerve growth factor receptor (NGFR) (Mehta et al. 2018). Collectively, these observations indicate that nongenetic adaptive responses occur in response to most, if not all, therapeutic modalities.

Microenvironment-driven transitions between phenotypes with substantially different sensitivities to targeted or immunotherapies represent a moving target and 
consequently pose a major challenge to effective therapy (Landsberg et al. 2012; Hugo et al. 2015; Emmons et al. 2016). However, the phenotypic plasticity of cancer cells also offers an opportunity for pharmacologic intervention aimed at diverting cells away from a drug-resistant state to one that is drug sensitive (Sáez-Ayala et al. 2013) or by targeting the events that lead to the generation or stabilization of specific phenotypic states (Gupta et al. 2009b; Rambow et al. 2018) However, to do so effectively requires an in-depth understanding of the molecular mechanisms underpinning cancer-associated phenotypic transitions, and knowledge of the repertoire of phenotypes present both prior to and as a consequence of therapy. Gene expression profiling of bulk tumors, exemplified by The Cancer Genome Atlas (TCGA) RNA-seq data sets from different tumor types, has revealed that individual tumors with a similar genetic profile may exhibit fundamentally different gene expression programs, reflecting different ratios of phenotypic states present within the cancer cell population as well as the contribution of noncancer cell types such as infiltrating immune cells or cancer-associated fibroblasts (CAFs) (Li et al. 2017; Racle et al. 2017; Finotello and Trajanoski 2018; Wang et al. 2018). Strikingly, the advent of next-generation sequencing, and in particular of single-cell sequencing profiling techniques, has revealed a high degree of genetic and transcriptomic complexity within the intra-tumor cellular landscape and provided key insights into the ability of both stromal and cancer cells to adapt to their changing microenvironment and therapeutic challenge (Tirosh et al. 2016; Fan et al. 2018; Jerby-Arnon et al. 2018; Lambrechts et al. 2018; Neftel et al. 2019). Nevertheless, despite the overwhelming body of evidence highlighting the cellular plasticity of cancer cells, primarily at the population level, the extent to which nongenetic reprogramming contributes to metastasis, drug tolerance, and/or resistance remains largely debated (Vanharanta and Massagué 2013; Vogelstein et al. 2013; Salgia and Kulkarni 2018). Below we use melanoma as a model to present a series of theoretical arguments coupled to recent experimental evidence highlighting key roles for nongenetic state switching at various steps of the evolution of disease progression and therapy resistance.

\section{Melanoma as a paradigm to study the contribution of phenotypic plasticity to metastasis and therapy resistance}

Cutaneous melanoma, a highly aggressive skin cancer arising from pigment-producing cells in the epidermis, is traditionally viewed as one of most metastatic malignancies and, consequently, can be regarded as a good model for examining the molecular mechanisms underpinning metastatic dissemination (Shain and Bastian 2016). Melanoma most commonly arises through activating mutations in BRAF or NRAS driving deregulated proliferation when combined with (usually solar UV irradiation-induced) genetic alterations and/or epigenetic events that promote senescence bypass (Bennett 2008; Shain and Bastian 2016). Notably, over the past 8 yr or so major advanc- es in melanoma therapy, from targeting oncogenic BRAF and MEK through to the breakthroughs in immunotherapies (Hodi et al. 2010; Chapman et al. 2011; Long et al. 2014; Robert et al. 2015a,b; Wolchok et al. 2017; Ascierto et al. 2019; Ribas et al. 2019) have led to important lessons for cancer therapy in general and highlighted the many challenges to successful treatment strategies. Indeed, the durable response rate to any approved therapy still remains relatively low and the vast majority of patients who initially respond to treatment later develop resistance (Luke et al. 2017; Jenkins et al. 2018). These data indicate that the success of future (immuno)therapeutic regimens will also, at least partly, depend on our ability to modulate nongenetic reprogramming events, such as stress- or inflammation-induced dedifferentiation (Landsberg et al. 2012; Falletta et al. 2017).

Most important, unlike many other cancers, welldefined biomarkers of distinct melanoma cellular phenotypic states have been identified and have provided key insights into the molecular mechanisms driving microenvironment-driven phenotype switching and their relationship to metastatic dissemination and therapy resistance. Note that although sometimes used, the term EMT is inappropriate for melanoma because melanocytes are not epithelial and their dedifferentiated invasive phenotype(s) may not be mesenchymal. Instead, the term phenotype switching, which was first introduced by Hoek (Fig. 1; Hoek et al. 2008), is becoming increasingly used to describe transitions between phenotypic states (Hoek and Goding 2010; Kemper et al. 2014). Rather than implying a directional switch between two predefined states (for example, epithelial to mesenchymal), phenotype switching is a neutral term that can be used to describe transitions between any phenotypic state without any preconception as to the nature of the changes in biological properties of the cells. Although phenotypic diversity and plasticity in melanoma cell lines has been described >30 yr ago (Fidler et al. 1981; Bennett 1983), the molecular characterization of specific phenotypic states was first refined with the cloning of the gene encoding the microphthalmia-associated transcription factor, MITF (Hodgkinson et al. 1993; Hughes et al. 1994), which has proved useful in defining specific phenotypic states imposed by microenvironmental signals.

\section{MITF and phenotype switching in melanoma}

Although the MITF gene was first isolated on the basis that its inactivation led to loss of all pigment cells in development (Hodgkinson et al. 1993; Hughes et al. 1994), it was rapidly recognized as a key regulator of genes implicated in melanogenesis (Goding 2000; Cheli et al. 2010), the primary differentiation-associated function of melanocytes. Moreover, early evidence also indicated that deregulation of MITF expression or activity by oncogenes such as adenovirus E1A could lead to dedifferentiation (Dooley et al. 1988; Wilson et al. 1989; Yavuzer et al. 1995). However, the role of MITF in melanoma and melanocytes has since been extended and now includes the 


\begin{tabular}{|c|c|c|c|c|c|c|}
\hline Hoek et al. 2008 & & Proliferative & \multicolumn{4}{|c|}{ Invasive } \\
\hline Hoek et al. 2006 & & A & \multicolumn{4}{|c|}{ C } \\
\hline Tsoi et al. 2018 & & $\begin{array}{c}\text { C4 } \\
\text { Melanocytic }\end{array}$ & $\begin{array}{c}\text { C3 } \\
\text { Transit }\end{array}$ & & $\begin{array}{c}\text { C1 } \\
\text { Undifferentiated }\end{array}$ & $\begin{array}{c}\text { C2 } \\
\text { Neural Crest-like }\end{array}$ \\
\hline Rambow et al. 2018 & Differentiated & Proliferative & & SMCs & Invasive & NCSCs \\
\hline $\begin{array}{c}\text { Proposed } \\
\text { Nomenclature }\end{array}$ & $\begin{array}{c}\text { Hyper- } \\
\text { Differentiated }\end{array}$ & Melanocytic & Intermediate & Starved & Undifferentiated & $\begin{array}{l}\text { Neural Crest } \\
\text { Stem Cell-like }\end{array}$ \\
\hline
\end{tabular}

Figure 1. Likely relationships between the phenotypic states of melanoma cells identified in different studies. Note that both the SMC and intermediate states appear to be related to the Tsoi et al. (2018) transitory state, but this remains to be formally established. regulation of genes implicated in several biological processes beyond differentiation such as survival (McGill et al. 2002), cell cycle control (Widlund et al. 2002; Carreira et al. 2005, 2006; Garraway et al. 2005), invasion (Carreira et al. 2006; Cheli et al. 2011, 2012), lysosome biogenesis (Ploper et al. 2015; Zhang et al. 2015b) and autophagy (Möller et al. 2019), senescence bypass (Giuliano et al. 2010), and DNA damage repair and chromosome stability (Giuliano et al. 2010; Strub et al. 2011). Since the role and regulation of MITF has recently been reviewed in depth (Goding and Arnheiter 2019), we only cover here the features of MITF expression and activity relevant for its association with specific melanoma phenotypic states.

MITF's role in regulating proliferation was initially confusing. Some groups provided evidence that it exerted a proproliferative role leading to MITF being termed a lineage addiction oncogene (Widlund et al. 2002; Garraway et al. 2005). In contrast, equally compelling evidence suggested that it could inhibit cell cycle progression and promote a differentiation-associated cell cycle arrest (Carreira et al. 2005; Loercher et al. 2005). These apparently conflicting observations were largely reconciled when Carreira et al (2006) proposed their rheostat model explaining the positive and negative role for MITF in melanoma proliferation (Carreira et al. 2006). In this model, low levels of MITF were associated with a G1 arrested or slow-cycling state characterized by high levels of the p27 cyclin-dependent kinase inhibitor and invasiveness. In contrast, expression of MITF promoted proliferation and suppressed invasiveness, whereas if MITF activity were further increased, a differentiation-associated G1 arrest would ensue. The rheostat model for MITF function was able to account for both the observed proproliferative role of MITF in driving an invasive to proliferative transition, but also for its anti-proliferative function in promoting a proliferative to differentiation switch. Moreover, the model explained the surprising observation that invasive MITF-depleted cells were G1 arrested or at least slow cycling (Carreira et al 2006; Cheli et al. 2011) and implied that for metastases to form, cells would need to transition from a proliferating state in the primary tumor to an invasive G1-arrested or slow-cycling state while invasive and then re-enter the cell cycle to fuel the growth of metastases. Since the initial observations showed G1 arrest and invasion could be triggered by using siRNA to deplete MITF in proliferating melanoma cells, it was proposed that regulating MITF expression and activity via the microenvironment would be a key driver of what has now become known as phenotype switching (Carreira et al. 2006). This prediction was nicely confirmed in a physiological setting using a temperature-sensitive MITF allele in zebrafish to control MITF activity (Lister et al. 2014). It was shown that a temperature shift leading to a reduction in MITF activity led to differentiated melanocytes re-entering the cell cycle. Similarly, differentiated, pigment-producing melanocytes in which a BRAF-driven melanomagenic program is introduced resume cell proliferation and, ultimately, promote the formation of aggressive and invasive melanoma in mice (Köhler et al. 2017).

In discussing the role of MITF in melanoma and melanocytes, and in particular the usefulness of MITF as a marker for specific phenotypic states, it is important to note that MITF activity will be determined by many factors, including its expression at the mRNA level, which is driven by a range of transcriptional activators and repressors and the signals that regulate them as well as microRNAs (Goding and Arnheiter 2019); its expression at the protein level, which is dictated by its translational control (Falletta et al. 2017; Phung et al. 2019) and protein stability (Wu et al. 2000; Xu et al. 2000; Ploper et al. 2015); the activity of the protein, which will be affected by posttranslational modifications that determine its nuclearcytoplasmic shuttling (Ngeow et al. 2018), interaction with cofactors (Sato et al. 1997; Price et al. 1998), or genome-wide distribution (Bertolotto et al. 2011); and the availability of DNA-binding partners and cofactors such as $\beta$-catenin (Schepsky et al. 2006) or the SWI/SNF complex (de la Serna et al. 2006). Although we can infer that cells lacking significant MITF mRNA expression will likely exhibit very low MITF protein expression, the expression of MITF mRNA does not necessarily imply either that the protein is expressed or that it is active. Nevertheless, mRNA or protein levels may represent a useful surrogate measure of activity, but we should always keep in mind that in an individual cell at any one time, mRNA and protein levels in an MITF-positive cell may not accurately reflect MITF function. Equally important, MITF may be active on some genes but not on others; it seems likely that posttranslational modifications that have yet to be defined may play a key role in directing MITF toward genes promoting proliferation versus those associated with differentiation, most notably those 
implicated in pigmentation. Although it has been proposed that expression of targets downstream from transcription factors may be viewed as a good surrogate readout of transcription factor activity (Schacht et al. 2014), for MITF this is more difficult given its ability to regulate both differentiation and proliferation, two biological states that may at times be mutually exclusive. Nevertheless, examination of the TCGA melanoma cohort tends to show that expression of pigmentation genes that are MITF targets appears by and large to mirror MITF mRNA expression.

Around the same time as the rheostat model for MITF function was proposed, a key study revealed that cell lines in culture reflected specific phenotypic states that could be defined by their gene expression profile (Hoek et al. 2006). Three cohorts of melanoma cell lines were identified. Cohort A expressed moderate to high levels of MITF, proliferated rapidly but were poorly invasive, whereas cohort $\mathrm{C}$ were characterized by low MITF, grew more slowly, and were more invasive (Fig. 1). Note that a high level of MITF in a cell line may, like low MITF levels, reduce the doubling time to some extent, but in order for the cell line to be established and be maintained the cells must tolerate high MITF without undergoing a differentiation-associated cell cycle arrest. Cohort B exhibited a mixed gene expression signature and over subsequent years has been largely ignored, although, as highlighted below, its significance may only now be emerging. Importantly, subsequent analysis revealed that in xenograft models, cell lines with gene expression patterns belonging to cohorts A and C could switch phenotypes in vivo (Hoek et al. 2008). Examination of MITF expression in melanomas also confirmed that its expression was low in tumors expressing a predominantly invasive gene expression signature and was high in tumors with a marked proliferative expression profile. Collectively, these data pointed toward the expression of MITF as a hallmark of specific phenotypic states and are consistent with observations that rare, stochastically generated, slow-cycling, and MITF-low cells within cultured melanoma cell lines are enriched in tumor-initiating capacity (Cheli et al. 2011). They also suggested that cell lines established originally from tumors exhibited invasive or proliferative phenotypes that had largely become fixed in culture, whereas they were more dynamic in vivo.

The notion that different melanoma phenotypes coexisted within melanoma in vivo was reinforced by the observation that MITF was expressed in a mutually exclusive fashion in tumors with the transcription factor BRN2 (POU3F2) (Goodall et al. 2008). Intravital imaging confirmed that individual cells with high activity of a BRN2GFP reporter were invasive, consistent with BRN2-positive cells being MITF-negative (Pinner et al. 2009). These observations led to a model in which BRN2 could directly repress MITF (Goodall et al. 2008), and MITF indirectly repressed BRN2 via miR-211 (Boyle et al. 2011). Such a positive feedback loop would impose a bi-stable state in which either, but not both, BRN2 or MITF would be expressed in individual cells. Thus, although BRN2 and MITF are coexpressed in many melanoma cell lines (Fane et al. 2019), growing these cell lines in 3D or in xenografts revealed that cells would segregate into the $\mathrm{MITF}^{\text {High }} / \mathrm{BRN} 2^{\text {Low }}$ and $\mathrm{MITF}^{\text {Low }} / \mathrm{BRN} 2^{\text {High }}$ phenotypes in vivo (Thurber et al. 2011). These data indicate that the microenvironment in vivo or in 3D has a dramatic effect on the behavior of MITF and BRN2 expression, leading to the establishment of distinct phenotypic states with different biological properties that is not apparent in cultured cells. An overwhelming body of data therefore indicates that at the population level melanoma cells can switch back and forth between a "proliferative" and an "invasive" cell state. Significantly, more recent evidence indicated that the dedifferentiated, invasive $\left(\mathrm{MITF}^{\mathrm{Low}}\right)$ phenotype is intrinsically resistant to MAPK pathway inhibitors and immunotherapies (Roesch et al. 2010; Kemper et al. 2014; Hugo et al. 2015, 2016; Verfaillie et al. 2015; Titz et al. 2016; Shaffer et al. 2017). Notably, several studies identified MITF ${ }^{\text {Low }}$ cells as expressing the AXL and EGFR receptor tyrosine kinases that are widely implicated in conferring resistance to MAPK pathway inhibition (Konieczkowski et al. 2014; Müller et al. 2014; Dugo et al. 2015).

Not surprisingly, a wide range of cellular stresses to which tumor cells are exposed are now known to downregulate MITF and at the same time promote invasiveness. These include hypoxia (Feige et al. 2011; Cheli et al. 2012; Louphrasitthiphol et al. 2019), low glucose (Ferguson et al. 2017) and amino acid limitation (Falletta et al. 2017), and inflammatory signaling, including transforming growth factor $\beta$ (TGF $\beta$ ) (Javelaud et al. 2011) and tumor necrosis factor $\alpha$ (TNFa) (Landsberg et al. 2012; Riesenberg et al. 2015; Falletta et al. 2017). Remarkably, all of these microenvironmental triggers of invasion converge on eIF2 $\alpha$ (Falletta et al. 2017; García-Jiménez and Goding 2019), a translation initiation factor that when phosphorylated on Serine 51 inhibits global translation initiation to suppress translation of MITF and increase invasion. At the same time p-eIF2 $\alpha$ also increases translation of ATF4 (Harding et al. 2000), a stress-responsive transcription factor that can repress MITF transcription (Falletta et al. 2017; Ferguson et al. 2017). Although depletion of MITF using siRNA can trigger invasion (Carreira et al. 2006), efficient suppression of MITF expression by ATF4 under nonstress conditions did not (Falletta et al. 2017). One interpretation of these experiments is that although low MITF activity is required for invasion, it is in itself insufficient. Indeed, invasion does not proceed unless the switch in translation mediated by p-eIF2 $\alpha$ also occurs. The role of translation reprogramming in cancer cell invasion and dedifferentiation is likely to be common as it has also been also associated with EMT in breast cancer (Nagelkerke et al. 2013; Feng et al. 2014).

We also note that whereas increased invasiveness arises within $24 \mathrm{~h}$ following siRNA-mediated MITF silencing (Carreira et al. 2006), longer-term depletion of MITF using siRNA can induce senescence (Giuliano et al. 2010). However, cell cycle arrest, but not senescence, is observed when MITF expression is silenced by ectopically expressing ATF4 or starving cells of glutamine (Falletta et al. 2017). It remains therefore unclear whether low MITF 
may be associated with senescence in the in vivo context or whether adaptive responses that would not be activated using MITF-targeting siRNAs prevent the occurrence of senescence.

\section{The increasing diversity of melanoma cell states}

\section{The MITF rheostat and 'intermediate' melanoma cells}

The MITF rheostat model has proven useful in describing how cells may reversibly switch phenotypes in vivo between differentiated, proliferative, and invasive states in response to microenvironmental cues that impose differential MITF activity. However, there is increasing evidence from real-time imaging and single-cell gene expression analyses that additional melanoma cell states exist and the current model to account for melanoma phenotypic heterogeneity needs to be revised. The effect of the intra-tumor microenvironment acting on intrinsically plastic cells has so far primarily been regarded as effecting reversible transitions between two distinct phenotypes, namely an MITF-positive and drug-sensitive proliferative state versus an MITF-low and drug-resilient invasive phenotype. However, while a useful approximation, increasing evidence indicates that this model is oversimplistic.

Although the term EMT implies transitions between two states, the related phenotypic changes appear to arise from more than a simple on-off switch. Several intermediate states, harboring distinct phenotypic features, can be identified between the extreme epithelial and mesenchymal states (Nieto et al. 2016; Pastushenko et al. 2018). Paralleling these observations, there is evidence that an intermediate melanoma state may exist in which cells exhibit a gene expression profile that lies between the "extreme" invasive and proliferative states. Such intermediate states may either reflect cells that are transiting from one state to another or represent a stable phenotypic checkpoint in which cells may reside before making the decision to either enter one state or another depending, for instance, on the pressure imposed by the microenvironment. Several lines of evidence point to the existence of such an intermediate phenotype(s).

First, the original Hoek et al. (2006) gene expression profiling of a large number of melanoma cell lines established that, in addition to the proliferative and invasive cohorts A and C, respectively, a few, termed cohort B, fell into neither the proliferative nor the invasive category (Fig. 1). The Hoek classification was later refined using gene expression analysis of a panel of 53 melanoma cell lines (Tsoi et al. 2018). In this study four classes of melanoma cells were identified, $\mathrm{C} 1-\mathrm{C} 4$. Class $\mathrm{C} 1$ and $\mathrm{C} 2$, both expressing the drug resistance marker $\mathrm{AXL}$, corresponded to the MITF $^{\text {Low }}$ and invasive Hoek cohort C (Fig. 1), but were distinguished by the expression of the transcription factors SOX9 in class $\mathrm{C} 1$ and SOX10 in class C2. Class C4 was the most differentiated, expressing MITF and a repertoire of differentiation-associated MITF targets and was related to Hoek's cohort A. Class C3 was related to Hoek's cohort B, expressing MITF, but also features of neural crest-like cells. The authors suggested the melanoma cell profiles corresponded to a four-stage differentiation model based on a comparison of the expression profiles of the $\mathrm{C} 1-\mathrm{C} 4$ classes and the repertoires of genes expressed as cells progress in an in vitro differentiation model from embryonic stem cells to differentiated melanocytes via a neural crest and melanoblast intermediates (Fig. 1). Importantly, the melanoma phenotypic subpopulation identified in cell lines by the Tsoi et al. (2018) and Hoek et al. (2006) studies reflected cell states detected in RNA-seq analysis of human tumors. The presence of cells with an intermediate phenotype between differentiation and invasion (cohort B/class C3) could arise either because each individual cell within the population examined expressed a gene expression profile that was truly intermediate between proliferative and invasive, because the cell lines contained mixed but stable subpopulations each reflecting the two different phenotypic states, or because cells were unstably flipping between one state and another with a specific frequency.

Second, using imaging of 3D melanoma spheres tagged with fluorescent reporters that permitted real-time integration of cell cycle, proliferation and invasion/migration revealed that some cells, especially those at the core of the sphere where hypoxia and nutrient limitation would occur, entered a reversible yet stable G1-arrested state (Haass et al. 2014). While, as expected, the G1-arrested cells were invasive, some of the proliferating cells also acquired invasive properties. The authors concluded that migration could occur independently of the proliferative status of the cells. They also noted that G1-arrested cells from the interior of the spheroid migrated more slowly than those from the periphery. Two distinct populations of invasive cells were thus identified: a G1-arrested and moderately invasive state, and one that is simultaneously proliferative and highly invasive and that arises when nutrients and oxygen are sufficient to support proliferation.

Third, conditional inactivation of the TGF $\beta$ inhibitory signaling factor Smad7 in a spontaneous mouse model of melanoma generated cells that were both highly proliferative and invasive. As a result, these compound mice develop fast growing primary melanomas and, at the same time, numerous and large metastatic lesions (Tuncer et al. 2019).

Fourth, under conditions of glutamine limitation multiple melanoma cell lines either became invasive or, for those with an already MITF ${ }^{\mathrm{Low}}$ invasive phenotype, increased their invasive capacity (Falletta et al. 2017). Glutamine limitation also induced a G1 arrest. The transition to a G1-arrested invasive state was underpinned by translation reprogramming. Nutrient limitation led to phosphorylation of the translation initiation factor eIF2 $\alpha$ that then inhibits the translation initiation factor eIF2B. As a consequence, phospho-eIF $2 \alpha$ reduces nutrient demand by down-regulating the translation of most transcripts while increasing translation of proteins that increase nutrient import and autophagy to restore nutrient supply. It was proposed that this translation switch was an evolutionarily conserved response to starvation that drives invasion in yeast as well as in other single cell organisms 
as a means to seek new nutrient supplies when experiencing resource limitation (Falletta et al. 2017; GarcíaJiménez and Goding 2019). Significantly, inducing the translation switch in nutrient rich conditions, using an inhibitor of the eIF2 $\alpha$ phosphatase, salubrinal, led to cells becoming invasive but maintaining proliferation (Falletta et al. 2017). These data essentially extend the observations from the 3D melanoma spheres (Haass et al. 2014) and reinforce the notion that melanoma cells can adopt a state that is simultaneously proliferative and invasive. Significantly, cells can reprogram translation in response to microenvironmental signals, including inflammatory cytokines, that can impose a pseudo-starvation state in which eIF $2 \alpha$ is phosphorylated in the presence of ample nutrients (García-Jiménez and Goding 2019). We therefore propose that pseudostarvation or a moderately reduced nutrient supply may permit invasion and proliferation to coexist as long as sufficient nutrients are available to support cell division. This is reminiscent of melanoblasts in development that migrate out of the neural crest to populate the skin and hair follicles but which also proliferate during their migration (Luciani et al. 2011). Notably, migrating MITF-positive melanoblasts express ATF4 (Suzuki et al. 2010) and their migration can be impaired by using the integrated stress response inhibitor ISRIB that prevents p-eIF2 $\alpha$-mediated inhibition of eIF2B (Falletta et al. 2017). Thus, at least some melanoblasts may reflect the proposed "intermediate" melanoma state in which cells can both proliferate and migrate.

Fifth, single-cell gene expression profiling also points toward an intermediate or poised state in which proliferative and invasive gene expression signatures are present. RT-qPCR profiling of single cells from a series of melanoma biopsies revealed the existence of cells simultaneously expressing genes that belong to both the MITF ${ }^{\text {High }}$ and MITF $^{\text {Low }}$ gene-expression signatures (Ennen et al. 2015, 2017). Although these studies only examined a limited repertoire of genes, they did highlight substantial heterogeneity in gene expression at the single-cell level; something that may have been missed when analyzing mRNA expression levels from bulk tumor samples or from cell lines.

Finally, by combining extensive profiling of single-cell gene expression and chromatin accessibility applied to more than 39,000 cells from a cohort of patient-derived melanoma cultures, Wouters et al. (2019) identified shared gene regulatory networks that underlie the extreme melanocytic and mesenchymal cell states as well as one stable intermediate state. The intermediate state was corroborated by a distinct open chromatin landscape and governed by the transcription factors EGR3, NFATC2, and RXRG, and exhibited intermediate MITF activity. Single-cell migration assays established that this "transition" state exhibits an intermediate migratory phenotype. This study also unraveled the sequential and recurrent arrangement of transcriptional programs at play during phenotype-switching that ultimately lead to the mesenchymal cell state.

The intermediate state therefore represents a cellular state that is distinct from the classical invasive and prolif- erative phenotypes. Instead "intermediate" cells express genes from both of these states and thereby are endowed with both invasive and proliferative properties. Note that this particular gene signature appears to be under the control of a unique gene regulatory network governed by a specific set of transcription factors. Thus, rather than simply exhibiting a transcription program that is an average of both end-states, "intermediate" cells may also harbor one that is discrete and confers specific phenotypic properties. It seems likely that by regulating translation of the expressed mRNAs, moderate levels of eIF2 $\alpha$ phosphorylation will be a major determinant of the intermediate phenotype. In this respect, although intermediate cells express MITF, it seems plausible that MITF activity (a combination of expression and function) will be lower than in a cell exhibiting a uniquely proliferative or melanocytic gene expression program.

\section{Phenotypic heterogeneity revealed by single-cell RNA sequencing}

While the contribution of translation reprogramming to cell phenotype at the single-cell level is as yet difficult to assess, the application of single cell RNA-seq (scRNAseq) is beginning to reveal the transcriptional programs underlying melanoma phenotypic heterogeneity. In the first study of its type, single-cell profiling of both malignant and stromal cells derived from tumors originating from 19 patients confirmed that MITF was a key biomarker for distinct phenotypic states (Tirosh et al. 2016). The results provided an important insight into the degree of phenotypic heterogeneity present within melanoma tumors. The analysis of genes associated with proliferating cells suggested that different tumors had significantly different proportions of cells in cycle ranging from $1 \%$ up to $30 \%$ despite the presence of similar oncogenic drivers. Moreover, isolation of cells from different parts of one tumor indicated regional differences in gene expression, with some areas exhibiting an inflammation-associated gene expression profile with features associated with drug-resistance. As expected, MITF was correlated with a differentiation gene-expression program and anti-correlated with AXL, associated with the invasive, dedifferentiated drug-resistance phenotype. Notably, treatment-naive tumors classified as MITF ${ }^{\text {High }}$ contained some cells with the AXL ${ }^{\text {High }}$ / MITF $^{\text {Low }}$ expression program, and treatment with BRAF inhibitor (BRAFi) or BRAFi plus MEKi led to an increased proportion of the AXL ${ }^{\text {High }} / M_{\text {ITF }}{ }^{\text {Low }}$ population, with a distinct resistant population of MET-high cells also being selected for. Additional information also was obtained regarding the contribution of nonmalignant cells. For example, the $\mathrm{AXL}^{\mathrm{High}} / \mathrm{MITF}^{\mathrm{Low}}$ population was associated with increased numbers of CAFs, whereas the MITF ${ }^{\text {High }}$ tumors exhibited reduced CAF infiltration. Taken together this single cell analysis, by and large, confirmed the coexistence of the MITF ${ }^{\text {High }}$ and MITF $^{\text {Low }}$ phenotypic states, and also revealed that rare drug-resistant cells were found in treatment naïve tumors that would otherwise be classified as MITF ${ }^{\text {High }}$ and, therefore, drug-sensitive. However, evidence for any intermediate state, as 
indicated by the Ennen et al. analyses (Ennen et al. 2015, 2017), was not readily apparent. This may be due to the relatively low number of cancer cells analyzed (i.e., only two tumors out of the 20 analyzed exhibited $>150$ malignant cells) and/or limited number of genes detected per cell due to inherent limitations of the scRNA-seq technique used for this analysis. Indeed, stable "states" within a given cell lineage are defined by the expression and activity of a discrete set of transcription factors that through bidirectional interactions with the chromatin landscape can give rise to specific gene-expression programs and, consequently, functional phenotypic states. Inferring cell states from single cell RNAseq data has become a powerful tool, yet is limited by a tradeoff between transcriptomic coverage per single cell and number of marker genes per cell state. For example, a cell state defined by 20 genes requires the expression information from $>2500$ genes/cell for reliable detection (Torre et al. 2018). Only scRNA-seq data of high quality, including a stringent downstream analysis, will be instrumental in extrapolating different states of melanoma cells.

This initial scRNA-seq analysis was highly informative with respect to the identification of distinct melanoma subpopulations at the single cell level, and the results were largely recapitulated in subsequent scRNA-seq analysis of short-term melanoma cultures with different driver mutations, most notably the bipolar expression of the MITF and AXL associated gene expression programs (Gerber et al. 2017; Loeffler-Wirth et al. 2018). Nevertheless, several questions remained unanswered. In particular, while tumors were examined pre- and posttherapy, the repertoire of drug-resistant cells in the minimal residual disease (MRD) state was not examined. Moreover, the phenotypic trajectory taken over time in response to microenvironmental stresses or therapy and how different phenotypic states might be established could not be readily inferred. Nor were any therapeutic vulnerabilities associated with specific phenotypic states identified.

A more recent single-cell analysis was performed on human melanoma cells isolated from patient-derived xenograft (PDX) mouse models exposed to MAPK therapeutics (Rambow et al. 2018). This study revealed an even greater complexity of melanoma state heterogeneity with respect to MITF expression (RNA and protein) in $\mathrm{BRAF}^{\mathrm{V} 600 \mathrm{E}}$ treatment-naïve tumors. Importantly, this phenotypic heterogeneity was exacerbated upon BRAF and MEK inhibition indicating that drug treatment can either impose phenotypic transitions or select for specific pre-existing phenotypic states. Significantly, different drug tolerant cell states coexisting within the same lesion exhibited distinct transcriptional MITF-(rheostat) activities (Rambow et al. 2018). scRNA-seq profiling of the PDX tumors before, during, and after BRAFi/MEKi combination therapy identified four distinct melanoma cell states associated with MRD, and the presence of these various melanoma subpopulations in clinical specimens was confirmed by in situ multiplexed immunohistochemistry. Note, however, that it cannot be ruled out that additional phenotypic states may exist in such clinical samples; for instance, arising as a result of inflamma- tory signaling from infiltrating immune cells. Such states are indeed likely to be missed in PDX lesions as these models lack key components of the adaptive immune system.

In keeping with a role for nutrient limitation in promoting generation of an MITF-intermediate state, one of the 4 cell states present at the MRD stage exhibited a dramatic down-regulation of an overall cancer cell metabolic signature (ccmGDB) (Kim et al. 2016) and shared transcriptomic features of nutrient-deprived cells (Kondo et al. 2017) including an elevated expression of the fatty acid translocase CD36. Termed the starved melanoma cell (SMC), (Fig. 1), bioinformatics analysis indicated that SMCs exhibited hallmarks of an MITF intermediate state characterized by features associated with both proliferation and invasion (Fig. 2). The expression of CD36 may confer a selective advantage to these cells by enabling more efficient uptake of fatty acids, thereby facilitating proliferation associated with metastasis formation. This has indeed been observed in dedifferentiated oral carcinoma cells (Pascual et al. 2017). The SMC state was underpinned, at least in part, by a transcriptional program dependent on PAX3, a transcription factor associated with development of the melanocyte lineage largely through its ability to promote MITF expression in melanoblasts (Bondurand et al. 2000; Potterf et al. 2000; Kubic et al. 2008). Notably, spatial analysis of drug-exposed lesions by multiplexed immunohistochemistry of human tumors demonstrated a nonrandom geographical organization of cells exhibiting a CD36-high starvation gene-expression profile as they were preferentially located within regions of tumors distant from blood vessels (Rambow

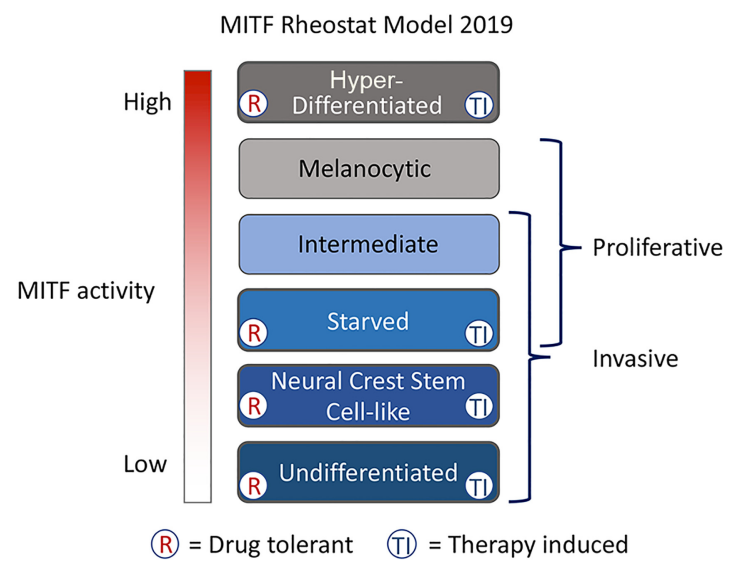

Figure 2. Revised rheostat model incorporating the six different phenotypic states found in melanoma to date. The states are ranked in relation their perceived MITF activity. Note that it is yet unclear whether the intermediate and starved (SMC) states are distinct. The hyper-differentiated, starved, NCSC and undifferentiated states are drug tolerant, and can also be enriched or induced by targeted therapy. It is also unclear whether the different states are related in a hierarchical fashion, though evidence suggests that the starved (SMC) state may be a precursor to the other drug-tolerant states, and whether proliferation is common to all cells of the melanocytic or intermediate states in vivo. 
et al. 2018), consistent with the possibility that a restricted nutrient or oxygen supply would contribute to the generation of the SMC phenotype in vivo.

In addition, two MITF-low/negative states were identified. One of these was reminiscent of a neural crest stemlike cell (NCSC) state that also exhibit features of the glial lineage as they express genes such as GFRA1-3, SOX10, and $G D N F$ in addition to markers of quiescent neural stem cells and glioblastoma proneural genes. The NCSC state was dramatically enriched upon MAPK inhibition. The other MITF-negative state was reminiscent of the invasive/mesenchymal-like state. Importantly, although the NCSC and classical invasive/mesenchymal-like states are both characterized by loss of MITF, these transcriptional states appear to represent two overlapping yet distinct subpopulations of melanoma cells. One major difference between the two undifferentiated MITF ${ }^{\text {Low }}$ states is the expression of SOX10, a key transcription factor usually thought to be associated with melanocyte identity through its capacity to promote MITF expression (Bondurand et al. 2000; Lee et al. 2000; Potterf et al. 2000; Verastegui et al. 2000) and cooperate with MITF in regulating a downstream gene-expression program (Fufa et al. 2015; Laurette et al. 2015). Importantly, whereas the classical invasive/mesenchymal-like state is devoid of SOX10 transcriptional activity, the NCSC state harbors a quiescent/dormant transcriptional program driven, at least in part, by SOX10/SOX2, NFAP2B, and RXRG. These observations are in good agreement with the Tsoi et al. (2018) study that transcriptionally profiled a large collection of melanoma cell lines and tumors to identify a four-stage differentiation model for melanoma; the invasive/mesenchymal and NCSC states identified through the single cell profiling of Rambow et al. (2018) appear to correspond to the undifferentiated C1 stage and neural crest C2 stage, respectively, characterized by Tsoi et al. (2018), while the SMC state, like the intermediate state, aligns with the Tsoi et al. (2018) C3 "transitory" phenotype (Fig. 1).

The NCSC state is also clearly distinct from the transient (pre-)resistant state recently derived from in vitro cultured melanoma cells exposed to BRAF inhibitor alone (Shaffer et al. 2017). In fact, this is only partly surprising as the gene expression signature of these so-called "jackpot" cells significantly overlaps with that described for the classical "invasive" cells. In contrast, the transcriptome of NCSCs presents some degree of similarity with the gene expression signatures obtained from bulk RNA-seq of drug-exposed melanoma cultures enriched for induced drug-tolerant cells (IDTCs) (Menon et al. 2015) and slow cycling NGFR-high cells (Fallahi-Sichani et al. 2017). Intriguingly, the drug-induced NCSC state is reminiscent of a developmentally plastic state induced during jaw regeneration (Ransom et al. 2018). This parallel indicates that tumor lesions exploit existing mechanisms at play in normal damaged tissues-such as induction of a stem cell-like state-to resist and recover from therapeutic insults. Collectively, these data indicate that there exists, at least, two distinct MITF-negative "dedifferentiated" states as well as intermediate and SMC states exhibiting both proliferative and invasive features. Together, these data prompted us to revisit the MITF-rheostat model so as to incorporate the newly identified phenotypic cell states (Fig. 2).

One hypothesis to explain the existence of these distinct states is that cells, depending on the growth conditions and stress level, may initiate various adaptive responses and behaviors (García-Jiménez and Goding 2019). An initial response to a stress situation leading to translation reprogramming may be to opt for an invasive/migratory behavior in quest of a more favorable environment and only subsequently adopt a more dormant or NCSC like dedifferentiated state if the stress is not resolved. This is similar to the phenotypic switch in bacteria from proliferation to invasion under stress conditions and subsequent sporulation or adoption of a drug-resistant persister cell state if the stress is not resolved (Vlamakis et al. 2008, 2013). By invoking different phenotypic responses depending on the severity and duration of the stress cells are exposed to, this model may help explain the origins of the different states identified in the studies outlined above. Note that composition of culture medium and concentrations of drugs used for these experiments may influence the outcome. Exposure of in vitro cultured melanoma cells, which are often grown in nutrient-rich medium supplemented with growth factors in excess, to a BRAF inhibitor alone may favor the transition into a dual invasive/proliferative "intermediate" cell state. In contrast, exposure of melanoma cells growing in a harsher in vivo microenvironment to the more clinically relevant BRAF/MEK inhibitor combination may instead favor entry into the dormant NCSC state.

In addition to the classical invasive, NCSC and SMC states, MAPK-inhibition can also induce a highly pigmented/hyperdifferentiated state (Figs. 1, 2) characterized by very high levels of MITF and expression of a large number of MITF-regulated genes, including those implicated in pigmentation. This MITF ${ }^{\text {High }}$ pigmented state can be uniformly induced in in vitro cultured melanoma cells exposed to a BRAF ${ }^{\mathrm{V} 600 \mathrm{E}}$ inhibitor (Smith et al. 2016), consistent with previous work that also identified both MITF $^{\text {High }}$ and MITF $^{\text {Low }}$ cells as being drug resistant (Müller et al. 2014). Single-cell RNA-seq and immunohistochemistry analyses later established that this subpopulation does emerge in vivo but not uniformly, as seen in vitro (Rambow et al. 2018). Rambow et al. (2018) indeed showed that whereas total MITF levels and activity are increased during treatment at the bulk level, single-cell analyses (both immunohistochemistry and scRNA-seq) showed that this overall increase can only be attributed to a fraction of cells. In vivo, the MITF ${ }^{\text {High }}$ cells are indeed surrounded by MITF ${ }^{\text {Low }}$ cells. Thus, melanomas can escape the deleterious effects of anti-cancer drugs by activating drug-resilient transcriptional programs that underpin multiple melanoma cell states, beyond the two wellknown "proliferative" and "invasive" phenotypes. Some of these cell states were identified in drug-naïve lesions (proliferative, invasive, and NCSCs) and were either enriched (invasive and NCSCs) or only emerging (SMCs and MITF $^{\text {High }}$ pigmented cells) following exposure to MAPK therapeutics (Fig. 2). 
As highlighted above, although distinct, the two MITF $^{\text {Low/Negative }}$ states share a large part of their specific gene expression signatures and are, thereby, likely to exhibit common phenotypic properties. Both states express a mesenchymal-like signature including genes regulated by TGF $\beta$ signaling, known to suppress MITF (Javelaud et al. 2011), promote invasion (likely linked to its capacity to promote translation reprogramming) (Feng et al. 2014) and extracellular matrix remodeling. This observation indicates that both states may be endowed with increased invasive properties, a prediction that has recently been validated experimentally (J-C Marine, unpubl.). The term "invasive" is therefore confusing as it no longer only applies to the classical invasive state, but also to the NCSC and to some of the above-described "intermediate state $(\mathrm{s})^{\prime \prime}$, including the SMCs. We therefore propose to revisit the nomenclature of the melanoma cell states and, as suggested by Tsoi et al. (2018), refer to the former "invasive" mesenchymal-like cells as the "undifferentiated" melanoma cells as they are indeed the most undifferentiated melanoma cells having lost expression of both melanocytic transcription factors SOX10 and MITF. We also propose to refer to the "proliferative" state as the melanocytic state, as other melanoma states (i.e., some intermediate state[s]) also exhibit proliferative capacity. Finally, we propose to refer to the remaining states as NCSC, starved melanoma cell (SMC) and hyper-differentiated states (Figs. 1, 2).

Note that while it is relatively simple to arrange the six different melanoma states identified to date in order of MITF expression or differentiation (Fig. 2), this does not necessarily reflect the potential of any one plastic state to generate another. Indeed, bioinformatic evidence (Rambow et al. 2018) indicates that it may be possible for the SMC state to act as a precursor to the differentiated, NCSC, and undifferentiated phenotypes, all of which are drug-tolerant states (Figs. 2, 3).

\section{Melanoma stem cells}

Multicolor lineage tracing approaches have revealed that, at least in some cancers, tumor growth is fueled by a limited population of cancer stem cells (CSCs) (Nassar and
Blanpain 2016; Batlle and Clevers 2017). A CSC has been defined as "a cell within a tumor that possesses the capacity to self-renew and to cause the heterogeneous lineages of cancer cells that comprise the tumor" (Clarke et al. 2006). In melanoma the existence of a stem cell population has been a matter of considerable debate. Attempts to search for such a cell population were made through transplantation experiments of a limited number of dissociated tumor cells into immunocompromised mice. This led to the identification of several markers of cells with enhanced tumor-initiating capacity, including the ABCB5 (Schatton et al. 2008), NGFR/CD271 (Boiko et al. 2010), CD34 (Held et al. 2010), and JARID1B (Roesch et al. 2010). Intriguingly, while the above-studies showed that only a small population of melanoma cells had tumor initiating capacity, others indicated that up to $25 \%$ of melanoma cells from dissociated tumors exhibited tumor-initiating capacity in NOD/SCID immunocompromised mice (Quintana et al. 2008). Subsequent work indicated that instead of a hierarchical organization, which would be compatible with the presence of CSCs, melanoma cells are capable of reversible state changes (Quintana et al. 2010), an observation that fits best with the phenotype switching model (Carreira et al. 2006; Hoek et al. 2008; Hoek and Goding 2010). Note, however, that the studies outlined above use transplantation into immunocompromised mice as a means to identification and characterization of CSCs or tumor-initiating cells. While this may be a useful tool (Beck and Blanpain 2013), this does not necessarily recapitulate the conditions melanoma cells are exposed to within established tumors. Our view is that while it is well established that melanoma cells can undergo dynamic and reversible phenotypic transitions, whether melanoma growth or relapse is fueled by a limited number of stem-like cells remains unclear and further careful in vivo multicolor lineage tracing analysis will be required to address this key issue.

\section{Exiting the lineage through transdifferentiation}

Given that cancer cells need to overcome many barriers to engender successful metastases, such as moving through

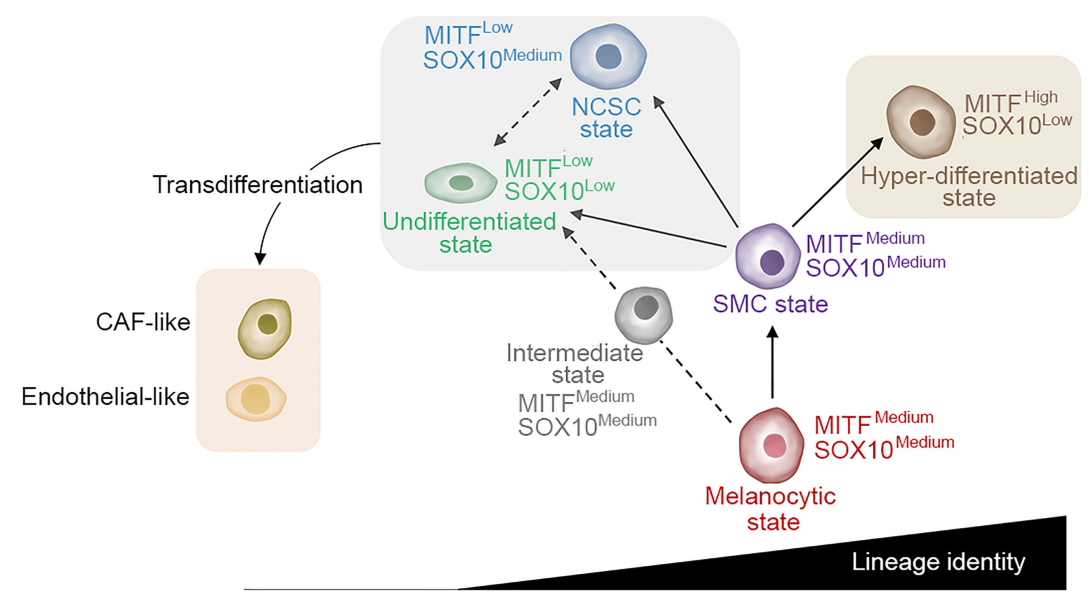

Figure 3. Potential hierarchical arrangement of the six different melanoma phenotypic states and their relative expression of MITF and SOX10. Also indicated are CAFs and endothelial cells that are presumed to be generated by transdifferentiation from the undifferentiated state. 
the walls of nearby lymph nodes and blood vessels and resisting anoikis and oxidative stress to survive in the bloodstream or in a foreign tumor microenvironment (TME) at secondary sites, it may be that yet additional melanoma cell states emerge during (and contribute to) metastatic dissemination. There is increasing evidence that melanoma cells can disseminate and colonize distant organs even before the manifestation of metastasis (Eyles et al. 2010; Sosa et al. 2014). It has been proposed that some melanoma cells may actually reside in the vasculature of the lungs (Ghajar et al. 2013), and be maintained in a dormant state for a prolonged period of time. Intriguingly, it has been reported that these cells may undergo transdifferentiation into an endothelial-like state (Fig. 3; Maniotis et al. 1999; Seftor et al. 2012). This "phenotype switch" would be accompanied by a decreased/loss of expression of melanoma markers and up-regulation of genes expressed specifically expressed in endothelial cells (i.e., $C D 31$, VE-cadherin). In vivo evidence supporting "vascular mimicry" is so far limited and its clinical and therapeutic relevance remain questionable. For example, it is not known whether such transdifferentiated cells are terminally differentiated or whether they might re-enter the cell cycle and thereby act as a reservoir of therapy-resistant melanoma cells. Moreover, for any transdifferentiation event it is not clear whether melanoma cells would first revert to a highly undifferentiated state with increased epigenetic plasticity and subsequently choose to adopt an alternative cell fate, or whether an alternative path to a different cellular identity might be taken.

Significantly, the undifferentiated melanoma phenotype, induced upon targeted therapy, shares many transcriptional features with CAFs to a point where a clear separation of both cell types becomes challenging (Tirosh et al. 2016). Nevertheless, a bidirectional crosstalk between CAFs and malignant cells has been firmly established. Highly glycolytic melanoma-associated CAFs can promote melanoma tumor growth in mouse models (Zhang et al. 2015a), and have been implicated in promoting resistance to BRAF inhibitor therapy by secretion of hepatocyte growth factor (HGF) (Straussman et al. 2012; Almeida et al. 2019). Consequently, the ability of therapy to induce melanoma cells to undergo "transdifferentiation" to a CAF-like phenotype is of significant clinical relevance.

Apart from therapy-induced transdifferentiation, unsaturated fatty acids can promote the acquisition by various cancer cell lines, including MALME-3M melanoma cells, of an adipogenic phenotype (Ruiz-Vela et al. 2011). Furthermore, a rare CD20+ positive melanoma subpopulation, grown in spheroids, was previously considered as a cancer-stem-like or tumor-initiating population given its ability to differentiate into adipocytes, amongst other lineages (Fang et al. 2005; Somasundaram et al. 2012).

Although the relevance of these transdifferentiation events has not yet been elucidated, the existence of transdifferentiated melanoma cells raises the possibility that additional uncharacterized melanoma cell states exist and highlight the need of using high-throughput scRNAseq to further dissect intratumoral heterogeneity.

\section{Implications and opportunities for therapy}

Efforts to understand the mechanisms of therapy resistance have highlighted an immense repertoire of mutation-dependent evasion mechanisms. In the context of melanoma MAPK targeted therapy, many genetic events including amplifications of the $B R A F$ gene and/or mutations in the NRAS, MEK1, MEK2, AKT1/3 genes among others, have been identified in many patients and sometimes even in one single patient (Spagnolo et al. 2014). The molecular nature of genetic mutations, such as point mutations that directly alter the target domain of protein kinases where selective inhibitor drugs bind (Knight et al. 2010; Sabnis and Bivona 2019) illustrates the power of "Darwinian" selection and highlight the need to improve effectiveness of treatment before mutational acquired resistance prevails. Indeed, treatment with multiple drugs targeting each of the different possible genetic resistance mechanisms that may be pre-existing or emerging within a single patient is not viable. Instead, we propose that future exploration of treatment options should contend with and capitalize on the possibilities afforded by melanoma cell plasticity and nongenetic tumor evolution to combat the almost inexorable development of resistance to anticancer drugs. In this respect, the recent and upcoming breakthroughs in the field of cancer therapeutics will undoubtedly lead to new and more effective treatments leading to an increasing number of patients with advanced metastatic disease experiencing complete remission (CR; reduction in tumor burden $>99 \%$ ). However, cancer therapy has to balance between killing tumor cells and avoiding host toxicity, thus limiting the dose used. Consequently, when combined with high microenvironment- and therapy-induced intratumor phenotypic heterogeneity, these new treatments will almost inevitably leave viable cancer cells in the form of MRD. The development of rational MRD-directed therapies is therefore timely and increasingly needed, and we therefore set out below a series of arguments that highlight the potential of rationally designed MRD-directed therapies aimed at intervening before stable (genetic) mechanisms of resistance are established (Fig. 4).

Since the probability of a cell population within a tumor harboring a mutation conferring resistance to a therapy is proportional to the number of cells, one key advantage of targeting MRD rather than waiting for clinical relapse is that the substantially reduced cancer cell numbers are significantly less likely to contain cells with genetic resistance. Moreover, patients may be able to better tolerate drugs with substantial side effects when only MRD is present compared with the time of fulminant relapse (Luskin et al. 2018). Even in the context of a high mutator disease, such as melanoma, it has been shown that resistance-conferring mutation-free tumors emerge in $\sim 40 \%$ of the cases (Hugo et al. 2015), a number that is expected to increase to close to $100 \%$ in tumors with a low mutational load. A strategy targeting MRD is therefore likely to lead to longlasting clinical benefits for a considerable number of patients. Nevertheless, the following considerations should be taken into account when designing such strategies. 


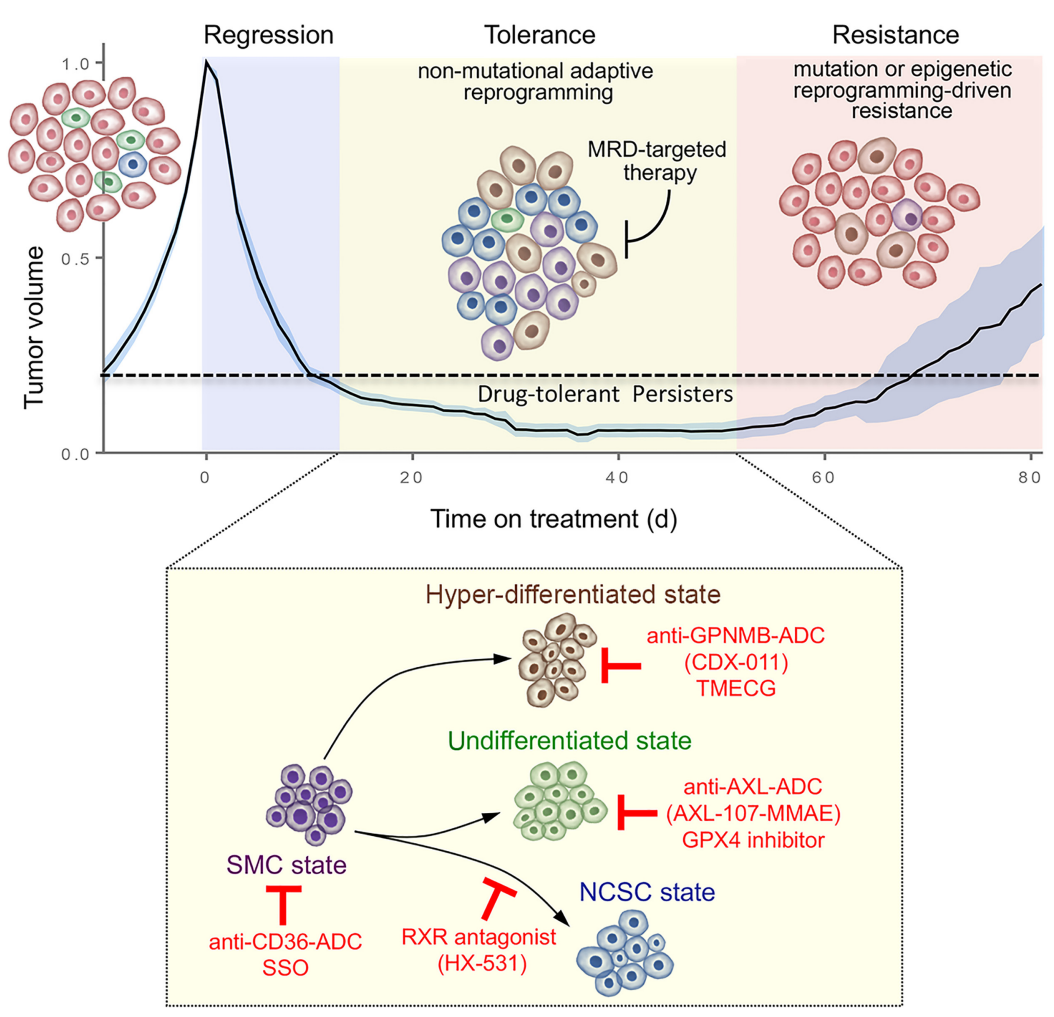

Figure 4. Potential therapeutic vulnerabilities of the four drug-tolerant persister cells found following targeted therapy. The persister cell population may act as a reservoir for drug-resistant relapse arising either through subsequent genetic mechanisms or via epigenetic reprogramming.
First, while mutation-less phenotype switching may be random and stochastic, genetic lesions may sensitize cells to microenvironmental cues by reducing the threshold above which a stochastic state transition can occur rather than directly promoting phenotypic transitions (Bernards and Weinberg 2002; Hoek and Goding 2010; García-Jiménez and Goding 2019|. Cell population dynamics with spontaneous conversions between drug-resistant and sensitive states (or between related proliferative and invasive phenotypes), can be subjected to "Darwinian" selection in the same manner as phenotype variability caused by mutations. In the presence of cytotoxic drugs, cells in a drugtolerant or resistant state that happen to be present prior treatment will have a growth advantage and will be gradually selected provided they remain in a proliferative or at least slowly cycling state. As these nongenetically fitter variants are present in the multimodal population due to a dynamic equilibrium, they are likely to exist at a much higher frequency than cells having acquired such phenotypic traits through a random DNA mutation.

Second, unlike random mutations in DNA, nongenetic phenotype switching is likely to turn on existing/evolved cellular programs (Hoek and Goding 2010; Hanahan and Weinberg 2011). Because of their longevity in tissues, normal stem cells, and by extension dormant or CSCs, are endowed with increased xenobiotic resistance. It is therefore perhaps not surprising that cell fate switching between a therapy-resistant state, which harbor CSC features and increased tumor-initiating capacity, and a more differentiated, drug-sensitive state has been observed in a number of tumor cell populations. In fact, the view that cancer therapy promotes emergence of dedifferentiated cells with
CSC features, and is thereby inherently a double-edge sword, is now supported by several reports (for examples, see Bao et al. 2006; Phillips et al. 2006; Woodward et al. 2007; Lee et al. 2011; Ghisolfi et al. 2012; Lagadec et al. 2012; Abubaker et al. 2013; Nör et al. 2014). These observations have stimulated the development of anti-CSC therapeutic strategies (Gupta et al. 2009b) often targeting surface markers and/or signaling pathways that are aberrantly activated and contribute to CSC proliferation and/or survival. Some of these therapeutic modalities are currently being tested in preclinical and clinical studies (Chen et al. 2013; Lathia and Liu 2017).

Third, enrichment of a specific drug-tolerant state may also occur through active, therapeutically induced, nongenetic reprogramming. The emergence of the drug-tolerant NCSCs in melanoma occurs through an active cell state transition rather than passive selection (Rambow et al. 2018). Such a directed somatic evolution toward an advantageous phenotype may be referred to as a "Lamarckian" induction: a better "adapted" inheritable state being induced by an environmental input. Evidence for such an adaptive mechanism in cancer has been reinforced by two recent studies (Su et al. 2017; Tsoi et al. 2018). Single-cell phenotyping was used to explore the response kinetics to BRAF inhibition of a panel of patient-derived $B R A F^{V 600 E}$ mutant melanoma cell lines. A subset of plastic cell lines, which followed a trajectory covering multiple known cell state transitions, provided models for more detailed biophysical investigations. Markov modeling revealed that the cell state transitions were reversible and mediated by both Lamarckian induction and nongenetic Darwinian selection of drug-tolerant states $(\mathrm{Su}$ et al. 
2017). Moreover, single-cell RNA sequencing showed that therapeutic resistance in Acute Myeloid Leukaemia (AML) emerges from a leukemia stem cell population in the form of a Lamarckian adaptive transcriptional response and, importantly, in the absence of genetic adaptation (Bell et al. 2019). Note that adaptive cell state transitions are especially likely to play a major role in drug resistance in tumors with a low mutation burden. The fact that this phenomenon is observed in cutaneous melanoma, the tumor type with the highest mutation load and mutator phenotype, suggests that "Lamarckian" induction is not uncommon, but rather a default reaction of cancer cells to massive, near-lethal perturbations.

Fourth, emergence of drug-tolerant cells in MRD may jump-start classical (mutation-based) somatic evolution by guaranteeing that there is always a small population of cells that can survive the treatment. Indeed, acquisition of the resistance phenotype may not even require de novo genetic alterations. Analyses of gene expression at singlecell resolution of in vitro cultured melanoma cells demonstrated that drug-resistant cells can emerge through a multistage process in which a few rare pre-existing cell subpopulations, expressing stochastically high levels of a number of resistance markers, are first selected for upon drug exposure and then converted into stably resistant cells through "epigenetic" reprogramming (Shaffer et al. 2017). Clinical studies showed that on-treatment melanomas regrow without any identifiable resistanceconferring genetic alterations (Rizos et al. 2014; Shi et al. 2014), consistent with $40 \%$ of resistant melanoma not being accounted for by any validated mutational mechanism (Hugo et al. 2015).

It seems likely that success will be achieved using a combination of immunotherapies or effective pharmcogenetic therapies, where drugs are matched to specific genetic drivers such as $B R A F^{V 600 E}$, together with new drug combinations that use a "pharmacophenomic" strategy aimed at exploiting the vulnerabilities associated with distinct phenotypes that may be independent of genetic driver mutations. Several pharmacophenomic strategies can be envisaged with preliminary evidence suggesting that targeting specific phenotypic subpopulations may be effective in delaying disease progression or eradicating specific phenotypic states that may exhibit a degree of interdependence. Such an approach may be especially effective if used to target the MRD state in which the genetic complexity of the surviving cells is low and defined resistant subpopulations have been identified.

Proof or principle that exploiting melanoma cell plasticity for therapeutic benefit by converting a drug-resistant population to one that is drug sensitive, an approach termed directed phenotype switching, has already been provided (Sáez-Ayala et al. 2013). In this report methotrexate (MTX) was shown to induce MITF levels and activity and therefore promote melanoma differentiation and reduce invasion. Consequently, the $\mathrm{MITF}^{\mathrm{High}} /$ differentiated cells were sensitive to a tyrosinase-processed antifolate prodrug TMECG. The MTX/TMECG combination delivered effective anti-melanoma responses in vitro and in mouse preclinical models. Although MTX is a chemother- apeutic agent which may cause severe adverse events in patients, the use of TMECG might possibly be effective in killing the $\mathrm{MITF}^{\mathrm{High}}$ pigmented population of therapy-resistant cells present in MRD following BRAF/MEK inhibitor therapy even without the use of MTX since these cells already exhibit high MITF levels and elevated pigmentation. Although TMECG-based therapy may only kill proliferating cells (Sáez-Ayala et al. 2013), its accumulation in cells after processing by melanosome-associated tyrosinase may mean that it would be an effective cytotoxic agent if the hyper-differentiated cells associated with MRD were to resume proliferation. Nevertheless, the dedifferentiated cells lacking tyrosinase expression in MRD would not be affected.

Significantly, several therapeutic vulnerabilities in the MITF $^{\text {Low }}$ populations and/or approaches to limit their emergence have already been identified. First, the NCSC population present in the MRD state was found to be established through the activity of the retinoic acid X receptor gamma (RXRG) (Rambow et al. 2018). Inhibiting this pathway with a pan-RXR antagonist attenuated the accumulation of NCSCs in drug-exposed melanoma cultures. These findings indicated that combining MAPK-targeting agents with RXR antagonists may significantly delay the onset of resistance, a prediction that was validated experimentally in a PDX preclinical setting (Fig. 4). However, this approach did not completely prevent relapse (Rambow et al. 2018). Nevertheless, these data support the notion that the NCSCs are an important reservoir of resistant cells, but several questions remain. For example, which cells managed to escape the effect of the RXR antagonist leading to ultimate relapse? The evidence available suggests that while the MAPKi/RXR antagonist combination attenuated emergence of NCSCs, it did so at the expense of a concomitant increase in the other three drug-tolerant states identified in MRD, with a particularly prominent increase in the $\mathrm{AXL}^{\mathrm{High}}$ invasive/dedifferentiated subpopulation. Since the targeting of this subpopulation is now possible through the use of the antibody-drug conjugate AXL-107-MMAE (Fig. 4; Boshuizen et al. 2018), it may be interesting in the future to test whether adding this molecule to a MAPKi/RXR antagonist regimen provide additional potential clinical benefit.

Second, by interrogating the Cancer Therapeutics Response Portal pharmacogenomics database Tsoi et al. (2018) discovered that the dedifferentiated state was highly sensitive to oxidative stress-induced ferroptosis, a form of iron-dependent programmed cell death. Ferroptosis is characterized by accumulation of lipid peroxides generated by oxidation of lipids on transfer of electrons to free radicals and arises as a consequence of reduced activity of the lipid repair enzyme glutathione peroxidase 4 (GPX4) (Dixon et al. 2012). Consistent with this, glutathione levels were reduced in dedifferentiated melanoma cells that were sensitive to ferroptosis inducers, whereas the pigment differentiated state was resistant to ferroptosis-inducing drugs and the neural crest-like state exhibited moderate sensitivity. Therapy-induced dedifferentiation driven by long-term BRAFi treatment also led to increased sensitivity to GPX4 inhibitors and importantly, the 
emergence of BRAFi-resistant populations was reduced by combination treatment with both vemurafenib and ferroptosis inducers (Fig. 4; Tsoi et al. 2018). Notably, ferroptosis inducers also promoted death in cell lines in which $\mathrm{TNFa}$ or IFN $\gamma$ induced dedifferentiation characterized by reduced MITF levels. Thus, in principle, ferroptosis inducers may be useful in reducing survival of cells exposed to microenvironmental stresses that drive melanoma dedifferentiation.

Third, it seems likely that metabolic differences between distinct phenotypic states may represent an important therapeutic vulnerability. For example, it has been established that in culture and in tumors, stochastically arising slow-cycling MITF-low cells, most likely related to the NCSC population of BRAFi-resistant cells, exhibit increased tumor-initiating potential (Cheli et al. 2011), are enriched in response to BRAF inhibition, and are required to fuel tumor expansion (Roesch et al. 2010). Significantly, the slow cycling population exhibits elevated oxidative phosphorylation at the expense of glycolysis (Roesch et al. 2013). As a consequence, targeting mitochondrial respiration blocked the emergence of the slow cycling population and overcame their nongenetic intrinsic drug resistance (Roesch et al. 2013). Likewise, the other drug tolerant, MITF $^{\text {High }}$, pigmented melanoma state may also exhibit exacerbated sensitivity to mitochondrial targeting agents. MITF controls the expression of PGC1a (PPARGC1A), a key factor implicated in mitochondrial biogenesis (Haq et al. 2013; Vazquez et al. 2013). Consequently, MITF ${ }^{\text {High }}$ melanoma subpopulations, which, as described above, can be induced upon exposure to MAPK therapeutics, express high levels of PGCla and are addicted to oxidative phosphorylation (Haq et al. 2013). Exposure of melanoma cells to various mitochondrial inhibitors, such as the mitochondrial uncoupler CCCP or inhibitors of oxidative phosphorylation (i.e., 2,4-DNP or oligomycin A) enhanced the efficacy of a BRAF $^{\mathrm{V} 600 \mathrm{E}}$ inhibitor in vitro. Yet another report showed that MAPKi substantially enhanced mitobiogenesis in surviving cells in a subset of BRAF mutated melanoma cell lines or patients' tumor biopsies that escaped shortterm inhibition of the MAPK pathway (Zhang et al. 2016). Targeting protein folding in mitochondria with the HSP90 inhibitor gamitrinib was effective in improving the efficacy of MAPKi in vitro and in xenografts and in preventing the acquisition of drug resistance to MAPKi in vitro. Although targeting mitochondrial function may not represent an ideal therapy in patients owing to toxicity (Pustylnikov et al. 2018), these studies do highlight the possibility that multiple phenotypic states may exhibit common metabolic vulnerabilities.

While searching for a common therapeutic strategy that may apply to most/all subpopulations of cells in MRD, it will be almost certainly necessary to identify complementary vulnerabilities if the disease is to be eradicated. For example, using vemurafenib to target proliferating melanoma cells, while at the same time promoting ferroptosis by using the GPX4 inhibitor RSL3 and/or using an RXR antagonist to kill cells on the trajectory toward an undifferentiated or NCSC-like phenotype (Fig. 4). It may also be interesting to test whether the addition of TMECG to any treatment regimen may provide additional potential clinical benefit by targeting the $\mathrm{MITF}^{\mathrm{High}} /$ differentiated cell population. Targeting $\mathrm{MITF}^{\mathrm{High}} /$ differentiated cells is also possible using a drug-conjugated antibody against GPNMB, a melanosomal antigen (Fig. 4; Rose et al. 2016; Ott et al. 2017). Combined with approaches specifically aimed at the MITF ${ }^{\text {Low }}$ dedifferentiated or NCSC populations these agents may prove useful in eradicating the MAPK pathway inhibitor-refractory pool of cells and convert targeted antimelanoma therapy into a curative approach. Note, however, that complete eradication of MRD may not be necessary. There may be some degree of interdependency between therapy-resistant subpopulations. For instance, recent evidence indicated that the MITF $^{\text {High }}$ state may instruct drug tolerance to neighboring cells in an ECE1-EDN1 paracrine fashion (Smith et al. 2017) and that, therefore, emergence of a specific "undifferentiated" state may be prevented upon depletion of these MITF $^{\text {High }}$ cells. Another interesting possibility is that ablation of the SMC subpopulation may be sufficient to provoke the collapse of the entire MRD lineage tree. Indeed, pseudo-time-ordering analyses indicated that the starved SMC transcriptional program may be the first melanoma cells switch on in response to MAPK inhibition, before making the decision to migrate along the differentiation or dedifferentiation trajectory paths (Fig. 4). Thus, although it remains to be established that the SMC state is required to reach the dedifferentiated (undifferentiated or NCSC) and/or pigmented state the prediction is that the SMCs may represent a therapeutically exploitable Achilles heel in order to prevent emergence of drug tolerance/resistance. Interestingly, these cells express high levels of the lipase translocase CD36. This receptor has been identified as a promising anticancer therapeutic target (Pascual et al. 2017) and several pharmacological means to target CD36-positive cells have been developed (Cheng et al. 2016). It will be interesting to target CD36-expressing cells using different strategies, such as the pharmacological inhibitor Sulfo-N-succinimidyl oleate (SSO) and CD36-neutralizing antibodies, while challenging melanoma cells with BRAF and MEK inhibitors in preclinical models and monitor the impact on MRD composition and time to progression (Fig. 4).

One may also envisage a more elaborate therapeutic strategy, one that diverts the fate of all/most distinct drug-tolerant persisters into a single (or limited numbers) of either permanently dormant and/or therapeutically sensitive state(s). For instance, forcing cells to adopt a dormant NCSC state may be a possible route toward this goal, as these cells are only transiently emerging and, by and large, disappear from lesions that ultimately grow on treatment. Therefore, even if these cells contribute to relapse they can only do so following transcriptional reprogramming into mitotically active cells, an event that could be prevented by agents that maintain the cells in their dormant NCSC state. Remarkably, pharmacological activation of RXR signaling using bexarotene was sufficient to enhance drug-induced entry into the NCSC state (Rambow et al. 2018). These data therefore suggest a 
two-step therapeutic strategy in which MAPK pathway targeting is first used to debulk the melanoma lesions and induce drug tolerance and in a second step, pharmacological activation of the GRN underlying the NCSC state is achieved by exposure to Bexarotene. This dormancy-directed strategy would limit heterogeneity of drug tolerance by forcing drug-tolerant cells to adopt a dormant NCSC phenotype. The cells may thus remain dormant for prolonged period of time and/or eventually be eradicated by taking advantage of their sensitivity to inhibitors that are yet to be identified. Because bexarotene is FDAapproved, such an approach would be rapidly amenable to clinical application. Importantly, this approach may be applicable to a large spectrum of patients, and not only to patients harboring $B R A F$ mutant melanomas, since NCSCs are also present in drug naïve NRAS mutant melanomas where expression levels of NCSC-specific markers increased in response to MEK-inhibition, an effect that was exacerbated upon addition to Bexarotene (Rambow et al. 2018).

The approaches outlined above take advantage of the well-proven efficacy of the BRAF/MEK inhibitor combination in patients with the aim of targeting a smaller pool of residual drug tolerant cells. Given the recent development of novel agents targeting NRAS-driven melanomas (Yin et al. 2019), MRD therapies may also eventually turn out to be applicable for this class of patients as well.

\section{Conclusions}

The evidence to date, obtained by gene expression profiling of melanoma cell lines and tumors as well as singlecell profiling and immunohistochemistry has identified a limited number of phenotypic states in melanoma with distinct gene-expression programs and biological properties. The six states so far characterized include: MITF $^{\text {High }}$ differentiated cells (hyper-differentiated state); MITF-positive proliferating cells (melanocytic state); an "intermediate" state related to migrating neural crest melanoblasts exhibiting an mixed gene expression profile with features of both invasion and proliferation, though whether all intermediate states identified by different groups are the same remains to be determined; a starved and/or therapy-induced SMC state (it remains unclear whether the SMC and intermediate states are actually distinct); and the MITF ${ }^{\text {Low }}$ NCSC and undifferentiated states. The phenotypic heterogeneity observed in vivo is caused by cell-intrinsic stresses generated by the activation of oncogenes, coupled with microenvironmental influences including hypoxia, nutrient limitation, and inflammatory signaling as well as stresses generated by therapy. Our view is that the different dedifferentiated phenotypes arise as a consequence of stress signaling imposing an adaptive response mediated by stress-responsive transcription factors such as ATF4 (Harding et al. 2003; Falletta et al. 2017; Ferguson et al. 2017), as well as translation reprogramming imposed by phosphorylation of eIF2a (García-Jiménez and Goding 2019). The degree of dedifferentiation will be determined by the amplitude and duration of the stress signals. Moderate stresses mediated by mildly reduced nutrient levels, inflammatory signals, or by low levels of therapeutic agents may generate the intermediate and/or SMC phenotypes, which may exhibit both invasive and proliferative profiles. In contrast, the more dedifferentiated states could arise if the adaptive responses fail to relieve the stress, or the amplitude of the stress signal increases. This would be consistent with the bioinformatic analysis that suggests that the intermediate or SMC phenotype may be a precursor to the NCSC and undifferentiated invasive states (Rambow et al. 2018). However, it is not clear how these two MITF-negative subpopulations of cells are related to one another. For example, the imposition of a positive feedback loop might induce a bistable state to generate either the NCSC or undifferentiated phenotype from an SMC or intermediate precursor. Alternatively, the NCSC state could represent a precursor to the undifferentiated phenotype. It is also not clear how the differentiated state characterized by high MITF and increased pigmentation is generated. Presumably, the mechanism is related to the physiological process of differentiation but exactly how it might be stabilized is not clear.

In a recent review (Bai et al. 2019), it has been proposed that the majority of cells within a melanoma tumor will exist in a continuous spectrum of states rather than fit any specific category and that the outliers will be the most unstable and therefore more likely to revert back to the most common state shared by the majority of cells. However, we feel it more likely that distinct melanoma phenotypes, once established, may become stabilized by positive feedback loops that then are fixed by epigenetic mechanisms. This is consistent with the observations of Shaffer et al. (2017) where transient drug-resistant phenotype was stabilized by epigenetic mechanisms, or that cell lines in culture exhibit gene expression profiles closely matching the different phenotypic subpopulations of cells observed in vivo. It would also be consistent with the observation that the $\mathrm{MITF}^{\mathrm{High}} / \mathrm{BRN} 2^{\text {Low }}$ and $\mathrm{MITF}^{\mathrm{Low}} /$ BRN2 ${ }^{\text {High }}$ populations are mutually exclusive within tumors (Goodall et al. 2008) and can potentially be induced by a miR-211-mediated positive feedback loop (Boyle et al. 2011). In this scenario, a specific phenotypic state may be self-sustaining, without the need for external signals for its maintenance. Inducing a phenotype switch would therefore require that a signal would change the activity of one of the components of the positive feedback loop, for example, by converting a transcriptional repressor into an activator or by reversing the epigenetic modifications responsible for stabilizing a specific phenotype. This is consistent with evidence suggesting that distinct phenotypic states are underpinned by defined transcription factor networks (Riesenberg et al. 2015; Verfaillie et al. 2015; Rambow et al. 2018; Wouters et al. 2019). Moreover, specific phenotypic states can become stabilized as evidenced by the fact that different cell lines in culture appear to have become fixed such that their gene-expression profiles (Hoek et al. 2006; Tsoi et al. 2018) reflect those identified using single cell RNA-seq 
approaches from tumors (Tirosh et al. 2016; Rambow et al. 2018).

The realization that both genetic and nongenetic ITH contribute to disease progression, therapy resistance, and relapse represents a major advance. However, the development of efficient curative therapies will require a greater understanding of the specific phenotypic states that promote disease progression and therapy resistance at single-cell resolution. For example, among the different phenotypic states that have been identified to date, which are primarily responsible for relapse? What are the characteristics of the cells that successfully seed metastases? How does the genetic background of the disease, for example, $B R A F$ versus NRAS driver mutations, affect the bidirectional interaction between the intratumor microenvironment and tumor cells that leads to the generation of distinct phenotypic subpopulations? Do different phenotypic subpopulations exhibit distinct therapeutic vulnerabilities beyond those we have already outlined? Are there specific hierarchies within cell states and do some cells exhibit properties associated with CSCs? Can small molecules be used to direct therapy-resistant phenotypes to become sensitive? Do the melanoma-derived endothelial-like cells constitute a reservoir of early disseminated and dormant cells from which metastasis inevitably originate?

Most of our understanding of microenvironment-driven intra-tumor heterogeneity and phenotype switching comes from cutaneous melanoma and little is known as to whether distinct phenotypic states exist in acral or mucosal melanoma. Nevertheless, gene expression profiling of uveal melanoma suggests two distinct phenotypes differentiated by either low or high risk that were characterized by differential expression of E-cadherin and the transcription factor Id 1 (Onken et al. 2004), and phenotypic plasticity has been observed in uveal melanoma cultures (Doherty et al. 2017). Thus, while uveal melanoma has a different genetic basis than cutaneous melanoma, being driven by activating mutations in GNAQ or GNA11 (Van Raamsdonk et al. 2009, 2010; Pandiani et al. 2017); nevertheless, it seems likely that phenotypic heterogeneity will play a key role in disease progression of noncutaneous melanomas.

The application of technologies aimed at dissecting intratumor heterogeneity at the single-cell level combined with innovative genetically engineered mouse models are likely to address many of these key questions. In particular, methodologies that capture the magnitude and dynamics of both genetic and nongenetic intra-tumor heterogeneity in the 4D (spatial and temporal) space and at single-cell resolution will be especially useful. Although the advent of reliable single-cell profiling techniques is currently revolutionizing our understanding of individual (cancer) cell behaviors within complex cellular systems/ populations, additional single-cell multi-Omics analytical tools, which allow the simultaneous profiling of the single-cell genome, (epi)genome, and transcriptome are particularly attractive. Population and clonal lineage tracing approaches should complement these analyses to validate lineage tracing trajectory inferences as has already been achieved in the olfactory cell lineage (Fletcher et al. 2017). Integrating lineage tracing and fate-mapping using cell state-specific Cre drivers and barcoding systems with single-cell profiling will provide a robust framework for defining cell fate transitions, intermediate states, and cell branching lineage trajectories and should facilitate the development of more effective therapies targeting specific phenotypic states independently of genotype.

\section{Acknowledgments}

C.R.G. is supported by the Ludwig Institute for Cancer Research and by National Institutes of Health grant PO1 CA128814-06A1. J.-C.M. is supported by grants from Melanoma Research Alliance (MRA; EIA\#623591), Stichting Tegen Kanker (STK), Interreg (Skin-Huid), FWO (\#G.0929.16N) and KUL (C1). F.R. received postdoctoral research fellowships from the Omics/Marie Curie@VIB.

\section{References}

Abubaker K, Latifi A, Luwor R, Nazaretian S, Zhu H, Quinn MA, Thompson EW, Findlay JK, Ahmed N. 2013. Short-term single treatment of chemotherapy results in the enrichment of ovarian cancer stem cell-like cells leading to an increased tumor burden. Mol Cancer 12: 24. doi:10.1186/1476-4598-12-24

Almeida FV, Douglass SM, Fane ME, Weeraratna AT. 2019. Bad company: Microenvironmentally mediated resistance to targeted therapy in melanoma. Pigment Cell Melanoma Res 32: 237-247. doi:10.1111/pcmr.12736

Andor N, Graham TA, Jansen M, Xia LC, Aktipis CA, Petritsch C, Ji HP, Maley CC. 2016. Pan-cancer analysis of the extent and consequences of intratumor heterogeneity. Nat Med 22: 105113. doi: $10.1038 / \mathrm{nm} .3984$

Ascierto PA, Ferrucci PF, Fisher R, Del Vecchio M, Atkinson V, Schmidt H, Schachter J, Queirolo P, Long GV, Di Giacomo AM, et al. 2019. Dabrafenib, trametinib and pembrolizumab or placebo in BRAF-mutant melanoma. Nat Med 25: 941946. doi:10.1038/s41591-019-0448-9

Bai X, Fisher DE, Flaherty KT. 2019. Cell-state dynamics and therapeutic resistance in melanoma from the perspective of MITF and IFN $\gamma$ pathways. Nat Rev Clin Oncol 16: 549-562. doi:10.1038/s41571-019-0204-6

Bao S, Wu Q, McLendon RE, Hao Y, Shi Q, Hjelmeland AB, Dewhirst MW, Bigner DD, Rich JN. 2006. Glioma stem cells promote radioresistance by preferential activation of the DNA damage response. Nature 444: 756-760. doi:10.1038/nature 05236

Batlle E, Clevers H. 2017. Cancer stem cells revisited. Nat Med 23: 1124-1134. doi:10.1038/nm.4409

Beck B, Blanpain C. 2013. Unravelling cancer stem cell potential. Nat Rev Cancer 13: 727-738. doi:10.1038/nrc3597

Bell CC, Fennell KA, Chan YC, Rambow F, Yeung MM, Vassiliadis D, Lara L, Yeh P, Martelotto LG, Rogiers A, et al. 2019. Targeting enhancer switching overcomes non-genetic drug resistance in acute myeloid leukaemia. Nat Commun 10: 2723. doi:10.1038/s41467-019-10652-9

Bennett DC. 1983. Differentiation in mouse melanoma cells: initial reversibility and an on-off stochastic model. Cell 34: 445453. doi:10.1016/0092-8674|83|90378-1

Bennett DC. 2008. How to make a melanoma: what do we know of the primary clonal events? Pigment Cell Melanoma Res 21: 27-38. doi:10.1111/j.1755-148X.2007.00433.x 
Bernards R, Weinberg RA. 2002. A progression puzzle. Nature 418: 823 . doi: $10.1038 / 418823$ a

Bertolotto C, Lesueur F, Giuliano S, Strub T, de Lichy M, Bille K, Dessen P, d'Hayer B, Mohamdi H, Remenieras A, et al. 2011. A SUMOylation-defective MITF germline mutation predisposes to melanoma and renal carcinoma. Nature 480: 94-98. doi:10 $.1038 /$ nature 10539

Boiko AD, Razorenova OV, van de Rijn M, Swetter SM, Johnson DL, Ly DP, Butler PD, Yang GP, Joshua B, Kaplan MJ, et al. 2010. Human melanoma-initiating cells express neural crest nerve growth factor receptor CD271. Nature 466: 133-137. doi:10.1038/nature09161

Bondurand N, Pingault V, Goerich DE, Lemort N, Sock E, Caignec CL, Wegner M, Goossens M. 2000. Interaction among SOX10, PAX3 and MITF, three genes altered in Waardenburg syndrome. Hum Mol Genet 9: 1907-1917. doi:10.1093/hmg/9 .13 .1907

Boshuizen J, Koopman LA, Krijgsman O, Shahrabi A, van den Heuvel EG, Ligtenberg MA, Vredevoogd DW, Kemper K, Kuilman T, Song JY, et al. 2018. Cooperative targeting of melanoma heterogeneity with an AXL antibody-drug conjugate and BRAF/MEK inhibitors. Nat Med 24: 203-212. doi:10.1038/ nm. 4472

Boyle GM, Woods SL, Bonazzi VF, Stark MS, Hacker E, Aoude LG, Dutton-Regester K, Cook AL, Sturm RA, Hayward NK. 2011. Melanoma cell invasiveness is regulated by miR-211 suppression of the BRN2 transcription factor. Pigment Cell Melanoma Res 24: 525-537. doi:10.1111/j.1755-148X.2011.00849.x

Brabletz T, Jung A, Spaderna S, Hlubek F, Kirchner T. 2005. Opinion: migrating cancer stem cells-an integrated concept of malignant tumour progression. Nat Rev Cancer 5: 744-749. doi:10.1038/nrc1694

Brandman O, Meyer T. 2008. Feedback loops shape cellular signals in space and time. Science 322: 390-395. doi:10.1126/sci ence. 1160617

Calkhoven CF, Ab G. 1996. Multiple steps in the regulation of transcription-factor level and activity. Biochem I 317: 329342. doi:10.1042/bj3170329

Carreira S, Goodall J, Aksan I, La Rocca SA, Galibert MD, Denat L, Larue L, Goding CR. 2005. Mitf cooperates with Rb1 and activates p21Cip1 expression to regulate cell cycle progression. Nature 433: 764-769. doi:10.1038/nature03269

Carreira S, Goodall J, Denat L, Rodriguez M, Nuciforo P, Hoek KS, Testori A, Larue L, Goding CR. 2006. Mitf regulation of Dia1 controls melanoma proliferation and invasiveness. Genes Dev 20: 3426-3439. doi:10.1101/gad.406406

Chaffer CL, Brueckmann I, Scheel C, Kaestli AJ, Wiggins PA, Rodrigues LO, Brooks M, Reinhardt F, Su Y, Polyak K, et al. 2011. Normal and neoplastic nonstem cells can spontaneously convert to a stem-like state. Proc Natl Acad Sci 108: 7950-7955. doi:10.1073/pnas.1102454108

Chaffer CL, San Juan BP, Lim E, Weinberg RA. 2016. EMT, cell plasticity and metastasis. Cancer Metastasis Rev 35: 645654. doi:10.1007/s10555-016-9648-7

Chapman PB, Hauschild A, Robert C, Haanen JB, Ascierto P, Larkin J, Dummer R, Garbe C, Testori A, Maio M, et al. 2011. Improved survival with vemurafenib in melanoma with BRAF V600E mutation. N Engl J Med 364: 2507-2516. doi:10.1056/ NEJMoa1 103782

Cheli Y, Ohanna M, Ballotti R, Bertolotto C. 2010. Fifteen-year quest for microphthalmia-associated transcription factor target genes. Pigment Cell Melanoma Res 23: 27-40. doi:10 $.1111 / j .1755-148 X .2009 .00653 . x$

Cheli Y, Giuliano S, Botton T, Rocchi S, Hofman V, Hofman P, Bahadoran P, Bertolotto C, Ballotti R. 2011. Mitf is the key molecular switch between mouse or human melanoma initiating cells and their differentiated progeny. Oncogene 30: 2307-2318. doi:10.1038/onc.2010.598

Cheli Y, Giuliano S, Fenouille N, Allegra M, Hofman V, Hofman P, Bahadoran P, Lacour JP, Tartare-Deckert S, Bertolotto C, et al. 2012. Hypoxia and MITF control metastatic behaviour in mouse and human melanoma cells. Oncogene 31: 24612470. doi:10.1038/onc.2011.425

Chen K, Huang YH, Chen JL. 2013. Understanding and targeting cancer stem cells: therapeutic implications and challenges. Acta Pharmacol Sin 34: 732-740. doi:10.1038/aps.2013.27

Cheng JJ, Li JR, Huang MH, Ma LL, Wu ZY, Jiang CC, Li WJ, Li YH, Han YX, Li H, et al. 2016. CD36 is a co-receptor for hepatitis C virus E1 protein attachment. Sci Rep 6: 21808. doi:10 $.1038 /$ srep2 1808

Chisholm RH, Lorenzi T, Lorz A, Larsen AK, de Almeida LN, Escargueil A, Clairambault J. 2015. Emergence of drug tolerance in cancer cell populations: an evolutionary outcome of selection, nongenetic instability, and stress-induced adaptation. Cancer Res 75: 930-939. doi:10.1158/0008-5472.CAN14-2103

Clarke MF, Dick JE, Dirks PB, Eaves CJ, Jamieson CH, Jones DL, Visvader J, Weissman IL, Wahl GM. 2006. Cancer stem cellsperspectives on current status and future directions: AACR Workshop on cancer stem cells. Cancer Res 66: 9339-9344. doi:10.1158/0008-5472.CAN-06-3126

Dallas NA, Xia L, Fan F, Gray MJ, Gaur P, van Buren G II, Samuel S, Kim MP, Lim SI, Ellis LM. 2009. Chemoresistant colorectal cancer cells, the cancer stem cell phenotype, and increased sensitivity to insulin-like growth factor-I receptor inhibition. Cancer Res 69: 1951-1957. doi:10.1158/0008-5472.CAN-082023

de la Serna IL, Ohkawa Y, Higashi C, Dutta C, Osias J, Kommajosyula N, Tachibana T, Imbalzano AN. 2006. The microphthalmia-associated transcription factor requires SWI/SNF enzymes to activate melanocyte-specific genes. I Biol Chem 281: 20233-20241. doi:10.1074/jbc.M512052200

Dixon SJ, Lemberg KM, Lamprecht MR, Skouta R, Zaitsev EM, Gleason CE, Patel DN, Bauer AJ, Cantley AM, Yang WS, et al. 2012. Ferroptosis: an iron-dependent form of nonapoptotic cell death. Cell 149: 1060-1072. doi:10.1016/j.cell.2012 .03 .042

Doherty RE, Sisley K, Hammond DW, Rennie IG, Cross NA. 2017. Phenotypic plasticity in uveal melanoma is not restricted to a tumor subpopulation and is unrelated to cancer stem cell characteristics. Invest Ophthalmol Vis Sci 58: 53875395. doi:10.1167/iovs.17-22272

Dongre A, Weinberg RA. 2019. New insights into the mechanisms of epithelial-mesenchymal transition and implications for cancer. Nat Rev Mol cell Biol 20: 69-84. doi:10.1038/ s41580-018-0080-4

Dooley TP, Wilson RE, Jones NC, Hart IR. 1988. Polyoma middle $\mathrm{T}$ abrogates TPA requirement of murine melanocytes and induces malignant melanoma. Oncogene 3: 531-535.

Dugo M, Nicolini G, Tragni G, Bersani I, Tomassetti A, Colonna V, Del Vecchio M, De Braud F, Canevari S, Anichini A, et al. 2015. A melanoma subtype with intrinsic resistance to BRAF inhibition identified by receptor tyrosine kinases gene-driven classification. Oncotarget 6: 5118-5133. doi:10 .18632/oncotarget.3007

Emmons MF, Faiao-Flores F, Smalley KS. 2016. The role of phenotypic plasticity in the escape of cancer cells from targeted therapy. Biochem Pharmacol 122: 1-9. doi:10.1016/j.bcp.2016.06 .014 
Ennen M, Keime C, Kobi D, Mengus G, Lipsker D, Thibault-Carpentier C, Davidson I. 2015. Single-cell gene expression signatures reveal melanoma cell heterogeneity. Oncogene 34: 3251-3263. doi:10.1038/onc.2014.262

Ennen M, Keime C, Gambi G, Kieny A, Coassolo S, Thibault-Carpentier C, Margerin-Schaller F, Davidson G, Vagne C, Lipsker D, et al. 2017. MITF-high and MITF-low cells and a novel subpopulation expressing genes of both cell states contribute to intra- and intertumoral heterogeneity of primary melanoma. Clin Cancer Res 23: 7097-7107. doi:10.1158/1078-0432.CCR$17-0010$

Eyles J, Puaux AL, Wang X, Toh B, Prakash C, Hong M, Tan TG, Zheng L, Ong LC, Jin Y, et al. 2010. Tumor cells disseminate early, but immunosurveillance limits metastatic outgrowth, in a mouse model of melanoma. I Clin Invest 120: 20302039. doi:10.1172/JCI42002

Fallahi-Sichani M, Becker V, Izar B, Baker GJ, Lin JR, Boswell SA, Shah P, Rotem A, Garraway LA, Sorger PK. 2017. Adaptive resistance of melanoma cells to RAF inhibition via reversible induction of a slowly dividing de-differentiated state. Mol Syst Biol 13: 905. doi:10.15252/msb.20166796

Falletta P, Sanchez-del-Campo L, Chauhan J, Effern M, Kenyon A, Kershaw CJ, Siddaway R, Lisle R, Freter R, Daniels M, et al. 2017. Translation reprogramming is an evolutionarily conserved driver of phenotypic plasticity and therapeutic resistance in melanoma. Genes Dev 31: 18-33. doi:10.1101/gad .290940 .116

Fan J, Lee HO, Lee S, Ryu DE, Lee S, Xue C, Kim SJ, Kim K, Barkas N, Park PJ, et al. 2018. Linking transcriptional and genetic tumor heterogeneity through allele analysis of single-cell RNAseq data. Genome Res 28: 1217-1227. doi:10.1101/gr.228080 .117

Fane ME, Chhabra Y, Smith AG, Sturm RA. 2019. BRN2, a POUerful driver of melanoma phenotype switching and metastasis. Pigment Cell Melanoma Res 32: 9-24. doi:10.1111/ pcmr. 12710

Fang D, Nguyen TK, Leishear K, Finko R, Kulp AN, Hotz S, Van Belle PA, Xu X, Elder DE, Herlyn M. 2005. A tumorigenic subpopulation with stem cell properties in melanomas. Cancer Res 65: 9328-9337. doi:10.1158/0008-5472.CAN-05-1343

Feige E, Yokoyama S, Levy C, Khaled M, Igras V, Lin RJ, Lee S, Widlund HR, Granter SR, Kung AL, et al. 2011. Hypoxia-induced transcriptional repression of the melanoma-associated oncogene MITF. Proc Natl Acad Sci 108: E924-E933. doi:10 $.1073 /$ pnas. 1106351108

Feng Y-XX, Sokol ES, Del Vecchio CA, Sanduja S, Claessen JH, Proia TA, Jin DX, Reinhardt F, Ploegh HL, Wang Q, et al. 2014. Epithelial-to-mesenchymal transition activates PERKeIF $2 \alpha$ and sensitizes cells to endoplasmic reticulum stress. Cancer Discov 4: 702-715. doi:10.1158/2159-8290.CD-130945

Ferguson J, Smith M, Zudaire I, Wellbrock C, Arozarena I. 2017. Glucose availability controls ATF4-mediated MITF suppression to drive melanoma cell growth. Oncotarget 8: 3294632959. doi:10.18632/oncotarget. 16514

Fidler IJ, Gruys E, Cifone MA, Barnes Z, Bucana C. 1981. Demonstration of multiple phenotypic diversity in a murine melanoma of recent origin. J Natl Cancer Inst 67: 947-956.

Filtz TM, Vogel WK, Leid M. 2014. Regulation of transcription factor activity by interconnected post-translational modifications. Trends Pharmacol Sci 35: 76-85. doi:10.1016/j.tips .2013.11.005

Finotello F, Trajanoski Z. 2018. Quantifying tumor-infiltrating immune cells from transcriptomics data. Cancer Immunol Immunother 67: 1031-1040. doi:10.1007/s00262-018-2150-z
Flavahan WA, Gaskell E, Bernstein BE. 2017. Epigenetic plasticity and the hallmarks of cancer. Science 357: eaal2380. doi:10 $.1126 /$ science.aal2380

Fletcher RB, Das D, Gadye L, Street KN, Baudhuin A, Wagner A, Cole MB, Flores Q, Choi YG, Yosef N, et al. 2017. Deconstructing olfactory stem cell trajectories at single-cell resolution. Cell Stem Cell 20: 817-830.e8. doi:10.1016/j.stem.2017 .04 .003

Fufa TD, Harris ML, Watkins-Chow DE, Levy D, Gorkin DU, Gildea DE, Song L, Safi A, Crawford GE, Sviderskaya EV, et al. 2015. Genomic analysis reveals distinct mechanisms and functional classes of SOX10-regulated genes in melanocytes. Hum Mol Genet 24: 5433-5450. doi:10.1093/hmg/ddv267

García-Jiménez C, Goding CR. 2019. Starvation and pseudo-starvation as drivers of cancer metastasis through translation reprogramming. Cell Metab 29: 254-267. doi:10.1016/j.cmet .2018 .11 .018

Garraway LA, Widlund HR, Rubin MA, Getz G, Berger AJ, Ramaswamy S, Beroukhim R, Milner DA, Granter SR, Du J, et al. 2005. Integrative genomic analyses identify MITF as a lineage survival oncogene amplified in malignant melanoma. Nature 436: $117-122$. doi: $10.1038 /$ nature 03664

Gerber T, Willscher E, Loeffler-Wirth H, Hopp L, Schadendorf D, Schartl M, Anderegg U, Camp G, Treutlein B, Binder H, et al. 2017. Mapping heterogeneity in patient-derived melanoma cultures by single-cell RNA-seq. Oncotarget 8: 846-862. doi:10.18632/oncotarget.13666

Gerlinger M, Swanton C. 2010. How Darwinian models inform therapeutic failure initiated by clonal heterogeneity in cancer medicine. Br I Cancer 103: 1139-1143. doi:10.1038/sj.bjc .6605912

Ghajar CM, Peinado H, Mori H, Matei IR, Evason KJ, Brazier H, Almeida D, Koller A, Hajjar KA, Stainier DY, et al. 2013. The perivascular niche regulates breast tumour dormancy. Nat Cell Biol 15: 807-817. doi:10.1038/ncb2767

Ghisolfi L, Keates AC, Hu X, Lee DK, Li CJ. 2012. Ionizing radiation induces stemness in cancer cells. PLoS One 7: e43628. doi:10.1371/journal.pone.0043628

Giancotti FG. 2013. Mechanisms governing metastatic dormancy and reactivation. Cell 155: 750-764. doi:10.1016/j .cell.2013.10.029

Giorgetti L, Siggers T, Tiana G, Caprara G, Notarbartolo S, Corona T, Pasparakis M, Milani P, Bulyk ML, Natoli G. 2010. Noncooperative interactions between transcription factors and clustered DNA binding sites enable graded transcriptional responses to environmental inputs. Mol Cell 37: 418-428. doi:10 .1016/j.molcel.2010.01.016

Giuliano S, Cheli Y, Ohanna M, Bonet C, Beuret L, Bille K, Loubat A, Hofman V, Hofman P, Ponzio G, et al. 2010. Microphthalmia-associated transcription factor controls the DNA damage response and a lineage-specific senescence program in melanomas. Cancer Res 70: 3813-3822. doi:10.1158/0008-5472 .CAN-09-2913

Goding CR. 2000. Mitf from neural crest to melanoma: signal transduction and transcription in the melanocyte lineage. Genes Dev 14: 1712-1728.

Goding CR, Arnheiter H. 2019. MITF-the first 25 years. Genes Dev 33: 983-1007. doi:10.1101/gad.324657.119

Goodall J, Carreira S, Denat L, Kobi D, Davidson I, Nuciforo P, Sturm RA, Larue L, Goding CR. 2008. Brn-2 represses microphthalmia-associated transcription factor expression and marks a distinct subpopulation of microphthalmia-associated transcription factor-negative melanoma cells. Cancer Res 68: 7788-7794. doi:10.1158/0008-5472.CAN-08-1053 
Gupta PB, Chaffer CL, Weinberg RA. 2009a. Cancer stem cells: mirage or reality? Nat Med 15: 1010-1012. doi:10.1038/ nm0909-1010

Gupta PB, Onder TT, Jiang G, Tao K, Kuperwasser C, Weinberg RA, Lander ES. 2009b. Identification of selective inhibitors of cancer stem cells by high-throughput screening. Cell 138: 645-659. doi:10.1016/j.cell.2009.06.034

Gupta PB, Fillmore CM, Jiang G, Shapira SD, Tao K, Kuperwasser C, Lander ES. 2011. Stochastic state transitions give rise to phenotypic equilibrium in populations of cancer cells. Cell 146: 633-644. doi:10.1016/j.cell.2011.07.026

Haass NK, Beaumont KA, Hill DS, Anfosso A, Mrass P, Munoz MA, Kinjyo I, Weninger W. 2014. Real-time cell cycle imaging during melanoma growth, invasion, and drug response. Pigment Cell Melanoma Res 27: 764-776. doi:10.1111/pcmr .12274

Hanahan D, Weinberg RA. 2011. Hallmarks of cancer: the next generation. Cell 144: 646-674. doi:10.1016/j.cell.2011.02.013

Haq R, Shoag J, Andreu-Perez P, Yokoyama S, Edelman H, Rowe GC, Frederick DT, Hurley AD, Nellore A, Kung AL, et al. 2013. Oncogenic BRAF regulates oxidative metabolism via PGCla and MITF. Cancer Cell 23: 302-315. doi:10.1016/j .ccr.2013.02.003

Harding HP, Novoa I, Zhang Y, Zeng H, Wek R, Schapira M, Ron D. 2000. Regulated translation initiation controls stress-induced gene expression in mammalian cells. Mol Cell 6: 1099-1108. doi:10.1016/S1097-2765(00)00108-8

Harding HP, Zhang Y, Zeng H, Novoa I, Lu PD, Calfon M, Sadri N, Yun C, Popko B, Paules R, et al. 2003. An integrated stress response regulates amino acid metabolism and resistance to oxidative stress. Mol Cell 11: 619-633. doi:10.1016/S10972765(03)00105-9

Held MA, Curley DP, Dankort D, McMahon M, Muthusamy V, Bosenberg MW. 2010. Characterization of melanoma cells capable of propagating tumors from a single cell. Cancer Res 70: 388-397. doi:10.1158/0008-5472.CAN-09-2153

Hodgkinson CA, Moore KJ, Nakayama A, Steingrímsson E, Copeland NG, Jenkins NA, Arnheiter H. 1993. Mutations at the mouse microphthalmia locus are associated with defects in a gene encoding a novel basic-helix-loop-helix-zipper protein. Cell 74: 395-404. doi:10.1016/0092-8674|93|90429-T

Hodi FS, O'Day SJ, McDermott DF, Weber RW, Sosman JA, Haanen JB, Gonzalez R, Robert C, Schadendorf D, Hassel JC, et al. 2010. Improved survival with ipilimumab in patients with metastatic melanoma. $N$ Engl I Med 363: 711-723. doi:10 .1056/NEJMoa1003466

Hoek K, Goding CR. 2010. Cancer stem cells versus phenotype switching in melanoma. Pigment Cell Melanoma Res 23: 746-759. doi:10.1111/j.1755-148X.2010.00757.x

Hoek KS, Schlegel NC, Brafford P, Sucker A, Ugurel S, Kumar R, Weber BL, Nathanson KL, Phillips DJ, Herlyn M, et al. 2006. Metastatic potential of melanomas defined by specific gene expression profiles with no BRAF signature. Pigment Cell Res 19: 290-302. doi:10.1111/j.1600-0749.2006.00322.x

Hoek KS, Eichhoff OM, Schlegel NC, Dobbeling U, Kobert N, Schaerer L, Hemmi S, Dummer R. 2008. In vivo switching of human melanoma cells between proliferative and invasive states. Cancer Res 68: 650-656. doi:10.1158/0008-5472.CAN07-2491

Huang RY, Wong MK, Tan TZ, Kuay KT, Ng AH, Chung VY, Chu YS, Matsumura N, Lai HC, Lee YF, et al. 2013. An EMT spectrum defines an anoikis-resistant and spheroidogenic intermediate mesenchymal state that is sensitive to e-cadherin restoration by a src-kinase inhibitor, saracatinib (AZD0530). Cell Death Dis 4: e915. doi:10.1038/cddis.2013.442
Hughes AE, Newton VE, Liu XZ, Read AP. 1994. A gene for Waardenburg syndrome type 2 maps close to the human homologue of the microphthalmia gene at chromosome 3p12p14.1. Nat Genet 7: 509-512. doi:10.1038/ng0894-509

Hugo W, Shi H, Sun L, Piva M, Song C, Kong X, Moriceau G, Hong A, Dahlman KB, Johnson DB, et al. 2015. Non-genomic and immune evolution of melanoma acquiring MAPKi resistance. Cell 162: 1271-1285. doi:10.1016/j.cell.2015.07.061

Hugo W, Zaretsky JM, Sun L, Song C, Moreno BH, Hu-Lieskovan S, Berent-Maoz B, Pang J, Chmielowski B, Cherry G, et al. 2016. Genomic and transcriptomic features of response to Anti-PD-1 therapy in metastatic melanoma. Cell 165: 3544. doi:10.1016/j.cell.2016.02.065

Jamal-Hanjani M, Quezada SA, Larkin J, Swanton C. 2015. Translational implications of tumor heterogeneity. Clin Cancer Res 21: 1258-1266. doi:10.1158/1078-0432.CCR-14-1429

Javelaud D, Alexaki VI, Pierrat MJ, Hoek KS, Dennler S, van Kempen L, Bertolotto C, Ballotti R, Saule S, Delmas V, et al. 2011. GLI2 and M-MITF transcription factors control exclusive gene expression programs and inversely regulate invasion in human melanoma cells. Pigment Cell Melanoma Res 24: 932-943. doi:10.1111/j.1755-148X.2011.00893.x

Jeggo PA, Pearl LH, Carr AM. 2016. DNA repair, genome stability and cancer: a historical perspective. Nat Rev Cancer 16: 35 42. doi:10.1038/nrc.2015.4

Jenkins RW, Barbie DA, Flaherty KT. 2018. Mechanisms of resistance to immune checkpoint inhibitors. Br J Cancer 118: 916. doi:10.1038/bjc. 2017.434

Jerby-Arnon L, Shah P, Cuoco MS, Rodman C, Su MJ, Melms JC, Leeson R, Kanodia A, Mei S, Lin JR, et al. 2018. A cancer cell program promotes $\mathrm{T}$ cell exclusion and resistance to checkpoint blockade. Cell 175: 984-997.e24. doi:10.1016/j.cell .2018.09.006

Joyce JA, Pollard JW. 2009. Microenvironmental regulation of metastasis. Nat Rev Cancer 9: 239-252. doi:10.1038/nrc2618

Kemper K, de Goeje PL, Peeper DS, van Amerongen R. 2014. Phenotype switching: tumor cell plasticity as a resistance mechanism and target for therapy. Cancer Res 74: 5937-5941. doi:10 .1158/0008-5472.CAN-14-1174

Kim P, Cheng F, Zhao J, Zhao Z. 2016. ccmGDB: a database for cancer cell metabolism genes. Nucleic Acids Res 44: D959D968. doi:10.1093/nar/gkv1128

Knight ZA, Lin H, Shokat KM. 2010. Targeting the cancer kinome through polypharmacology. Nat Rev Cancer 10: 130-137. doi:10.1038/nrc2787

Köhler C, Nittner D, Rambow F, Radaelli E, Stanchi F, Vandamme N, Baggiolini A, Sommer L, Berx G, van den Oord JJ, et al. 2017. Mouse cutaneous melanoma induced by mutant BRaf arises from expansion and dedifferentiation of mature pigmented melanocytes. Cell Stem Cell 21: 679-693.e6. doi:10.1016/j.stem.2017.08.003

Kondo A, Yamamoto S, Nakaki R, Shimamura T, Hamakubo T, Sakai J, Kodama T, Yoshida T, Aburatani H, Osawa T. 2017. Extracellular acidic $\mathrm{pH}$ activates the sterol regulatory element-binding protein 2 to promote tumor progression. Cell Rep 18: 2228-2242. doi:10.1016/j.celrep.2017.02.006

Konieczkowski DJ, Johannessen CM, Abudayyeh O, Kim JW, Cooper ZA, Piris A, Frederick DT, Barzily-Rokni M, Straussman R, Haq R, et al. 2014. A melanoma cell state distinction influences sensitivity to MAPK pathway inhibitors. Cancer Discov 4: 816-827. doi:10.1158/2159-8290.CD-13-0424

Koyama S, Akbay EA, Li YY, Herter-Sprie GS, Buczkowski KA, Richards WG, Gandhi L, Redig AJ, Rodig SJ, Asahina H, et al. 2016. Adaptive resistance to therapeutic PD-1 blockade 
is associated with upregulation of alternative immune checkpoints. Nat Commun 7: 10501. doi:10.1038/ncomms10501

Kubic JD, Young KP, Plummer RS, Ludvik AE, Lang D. 2008. Pigmentation PAX-ways: the role of Pax3 in melanogenesis, melanocyte stem cell maintenance, and disease. Pigment Cell Melanoma Res 21: 627-645. doi:10.1111/j.1755-148X.2008 .00514.x

Lagadec C, Vlashi E, Della Donna L, Dekmezian C, Pajonk F. 2012. Radiation-induced reprogramming of breast cancer cells. Stem Cells 30: 833-844. doi:10.1002/stem.1058

Lambrechts D, Wauters E, Boeckx B, Aibar S, Nittner D, Burton O, Bassez A, Decaluwé H, Pircher A, Van den Eynde K, et al. 2018. Phenotype molding of stromal cells in the lung tumor microenvironment. Nat Med 24: 1277-1289. doi:10.1038/ s41591-018-0096-5

Landsberg J, Kohlmeyer J, Renn M, Bald T, Rogava M, Cron M, Fatho M, Lennerz V, Wölfel T, Hölzel M, et al. 2012. Melanomas resist T-cell therapy through inflammation-induced reversible dedifferentiation. Nature 490: 412-416. doi:10.1038/ nature 11538

Lathia JD, Liu H. 2017. Overview of cancer stem cells and stemness for community oncologists. Target Oncol 12: 387-399. doi:10.1007/s11523-017-0508-3

Laurette P, Strub T, Koludrovic D, Keime C, Le Gras S, Seberg H, Van Otterloo E, Imrichova H, Siddaway R, Aerts S, et al. 2015. Transcription factor MITF and remodeller BRG1 define chromatin organisation at regulatory elements in melanoma cells. Elife 4: e06857. doi:10.7554/eLife.06857

Lee M, Goodall J, Verastegui C, Ballotti R, Goding CR. 2000. Direct regulation of the Microphthalmia promoter by Sox 10 links Waardenburg-Shah syndrome (WS4)-associated hypopigmentation and deafness to WS2. I Biol Chem 275: 3797837983. doi:10.1074/jbc.M003816200

Lee GY, Shim JS, Cho B, Jung JY, Lee DS, Oh IH. 2011. Stochastic acquisition of a stem cell-like state and drug tolerance in leukemia cells stressed by radiation. Int I Hematol 93: 27-35. doi:10.1007/s12185-010-0734-2

Lehuédé C, Dupuy F, Rabinovitch R, Jones RG, Siegel PM. 2016. Metabolic plasticity as a determinant of tumor growth and metastasis. Cancer Res 76: 5201-5208. doi:10.1158/00085472.CAN-16-0266

Li Y, Kang K, Krahn JM, Croutwater N, Lee K, Umbach DM, Li L. 2017. A comprehensive genomic pan-cancer classification using The Cancer Genome Atlas gene expression data. BMC Genomics 18: 508. doi:10.1186/s12864-017-3906-0

Lister JA, Capper A, Zeng Z, Mathers ME, Richardson J, Paranthaman K, Jackson IJ, Patton EE. 2014. A conditional zebrafish MITF mutation reveals MITF levels are critical for melanoma promotion vs. regression in vivo. J Invest Dermatol 134: 133140. doi:10.1038/iid.2013.293

Loeffler-Wirth H, Binder H, Willscher E, Gerber T, Kunz M. 2018. Pseudotime dynamics in melanoma single-cell transcriptomes reveals different mechanisms of tumor progression. Biology (Basel) 7: E23. doi:10.3390/biology7020023

Loercher AE, Tank EM, Delston RB, Harbour JW. 2005. MITF links differentiation with cell cycle arrest in melanocytes by transcriptional activation of INK4A. J Cell Biol 168: 35-40. doi:10.1083/jcb.200410115

Lohr JG, Stojanov P, Carter SL, Cruz-Gordillo P, Lawrence MS, Auclair D, Sougnez C, Knoechel B, Gould J, Saksena G, et al. 2014. Widespread genetic heterogeneity in multiple myeloma: implications for targeted therapy. Cancer Cell 25: 91101. doi:10.1016/j.ccr.2013.12.015

Long GV, Stroyakovskiy D, Gogas H, Levchenko E, de Braud F, Larkin J, Garbe C, Jouary T, Hauschild A, Grob JJ, et al.
2014. Combined BRAF and MEK inhibition versus BRAF inhibition alone in melanoma. $N$ Engl I Med 371: 1877-1888. doi:10.1056/NEJMoa1406037

Louphrasitthiphol P, Ledaki I, Chauhan J, Falletta P, Siddaway R, Buffa FM, Mole DR, Soga T, Goding CR. 2019. MITF controls the TCA cycle to modulate the melanoma hypoxia response. Pigment Cell Melanoma Res. doi:10.1111/pcmr.12802

Lu M, Muers MR, Lu X. 2016. Introducing STRaNDs: shuttling transcriptional regulators that are non-DNA binding. Nat Rev Mol Cell Biol 17: 523-532. doi:10.1038/nrm.2016.41

Luciani F, Champeval D, Herbette A, Denat L, Aylaj B, Martinozzi S, Ballotti R, Kemler R, Goding CR, De Vuyst F, et al. 2011. Biological and mathematical modeling of melanocyte development. Development 138: 3943-3954. doi:10.1242/ dev.067447

Luke JJ, Flaherty KT, Ribas A, Long GV. 2017. Targeted agents and immunotherapies: optimizing outcomes in melanoma. Nat Rev Clin Oncol 14: 463-482. doi:10.1038/nrclinonc .2017 .43

Luskin MR, Murakami MA, Manalis SR, Weinstock DM. 2018. Targeting minimal residual disease: a path to cure? Nat Rev Cancer 18: 255-263. doi:10.1038/nrc.2017.125

Maniotis AJ, Folberg R, Hess A, Seftor EA, Gardner LM, Pe'er J, Trent JM, Meltzer PS, Hendrix MJ. 1999. Vascular channel formation by human melanoma cells in vivo and in vitro: vasculogenic mimicry. Am I Pathol 155: 739-752. doi:10.1016/ S0002-9440(10)65173-5

McGill GG, Horstmann M, Widlund HR, Du J, Motyckova G, Nishimura EK, Lin YL, Ramaswamy S, Avery W, Ding HF, et al. 2002. Bcl2 regulation by the melanocyte master regulator mitf modulates lineage survival and melanoma cell viability. Cell 109: 707-718. doi:10.1016/S0092-8674(02)00762-6

McGranahan N, Swanton C. 2015. Biological and therapeutic impact of intratumor heterogeneity in cancer evolution. Cancer Cell 27: 15-26. doi:10.1016/j.ccell.2014.12.001

Mehta A, Kim YJ, Robert L, Tsoi J, Comin-Anduix B, Berent-Maoz B, Cochran AJ, Economou JS, Tumeh PC, Puig-Saus C, et al. 2018. Immunotherapy resistance by inflammation-induced dedifferentiation. Cancer Discov 8: 935-943. doi:10.1158/ 2159-8290.CD-17-1178

Menon DR, Das S, Krepler C, Vultur A, Rinner B, Schauer S, Kashofer K, Wagner K, Zhang G, Rad EB, et al. 2015. A stress-induced early innate response causes multidrug tolerance in melanoma. Oncogene 34: 4448-4459. doi:10.1038/ onc. 2014.432

Möller K, Sigurbjornsdottir S, Arnthorsson AO, Pogenberg V, Dilshat R, Fock V, Brynjolfsdottir SH, Bindesboll C, Bessadottir M, Ogmundsdottir HM, et al. 2019. MITF has a central role in regulating starvation-induced autophagy in melanoma. Sci Rep 9: 1055. doi:10.1038/s41598-018-37522-6

Mroz EA, Rocco JW. 2013. MATH, a novel measure of intratumor genetic heterogeneity, is high in poor-outcome classes of head and neck squamous cell carcinoma. Oral Oncol 49: 211-215. doi:10.1016/j.oraloncology.2012.09.007

Müller J, Krijgsman O, Tsoi J, Robert L, Hugo W, Song C, Kong X, Possik PA, Cornelissen-Steiger PD, Foppen MH, et al. 2014. Low MITF/AXL ratio predicts early resistance to multiple targeted drugs in melanoma. Nat Commun 5: 5712. doi:10.1038/ ncomms 6712

Nagelkerke A, Bussink J, Mujcic H, Wouters BG, Lehmann S, Sweep FC, Span PN. 2013. Hypoxia stimulates migration of breast cancer cells via the PERK/ATF4/LAMP3-arm of the unfolded protein response. Breast Cancer Res 15: R2. doi:10 $.1186 /$ bcr3373 
Nassar D, Blanpain C. 2016. Cancer stem cells: Basic concepts and therapeutic implications. Annu Rev Pathol 11: 47-76. doi:10.1146/annurev-pathol-012615-044438

Neftel C, Laffy J, Filbin MG, Hara T, Shore ME, Rahme GJ, Richman AR, Silverbush D, Shaw ML, Hebert CM, et al. 2019. An integrative model of cellular states, plasticity, and genetics for glioblastoma. Cell 178: 835-849.e21. doi:10.1016/j.cell.2019 .06 .024

Ngeow KC, Friedrichsen HI, Li L, Zeng Z, Andrews S, Volpon L, Brunsdon H, Berridge G, Picaud S, Fischer R, et al. 2018. BRAF/MAPK and GSK3 signaling converges to control MITF nuclear export. Proc Natl Acad Sci 115: E8668-8677. doi:10.1073/pnas.1810498115

Nieto MA, Huang RY, Jackson RA, Thiery JP. 2016. Emt: 2016. Cell 166: 21-45. doi:10.1016/j.cell.2016.06.028

Nör C, Zhang Z, Warner KA, Bernardi L, Visioli F, Helman JI, Roesler R, Nör JE. 2014. Cisplatin induces Bmi-1 and enhances the stem cell fraction in head and neck cancer. Neoplasia 16: 137-146. doi:10.1593/neo.131744

Nowell PC. 1976. The clonal evolution of tumor cell populations. Science 194: 23-28. doi:10.1126/science.959840

Ocana OH, Córcoles R, Fabra A, Moreno-Bueno G, Acloque H, Vega S, Barrallo-Gimeno A, Cano A, Nieto MA. 2012. Metastatic colonization requires the repression of the epithelialmesenchymal transition inducer Prrx1. Cancer Cell 22: 709724. doi:10.1016/j.ccr.2012.10.012

Onken MD, Worley LA, Ehlers JP, Harbour JW. 2004. Gene expression profiling in uveal melanoma reveals two molecular classes and predicts metastatic death. Cancer Res 64: 72057209. doi:10.1158/0008-5472.CAN-04-1750

Ott PA, Pavlick AC, Johnson DB, Hart LL, Infante JR, Luke JJ, Lutzky J, Rothschild NE, Spitler LE, Cowey CL, et al. 2017. A phase II study of glembatumumab vedotin (GV), an antibody-drug conjugate (ADC) targeting gpNMB, in advanced melanoma. J Clin Oncol 35: 109. doi:10.1200/JCO.2017.35 .15_suppl.109

Pandiani C, Béranger GE, Leclerc J, Ballotti R, Bertolotto C. 2017. Focus on cutaneous and uveal melanoma specificities. Genes Dev 31: 724-743. doi:10.1101/gad.296962.117

Pascual G, Avgustinova A, Mejetta S, Martín M, Castellanos A, Attolini CS-O, Berenguer A, Prats N, Toll A, Hueto JA, et al. 2017. Targeting metastasis-initiating cells through the fatty acid receptor CD36. Nature 541: 41-45. doi:10.1038/ nature 20791

Pastushenko I, Brisebarre A, Sifrim A, Fioramonti M, Revenco T, Boumahdi S, Van Keymeulen A, Brown D, Moers V, Lemaire S, et al. 2018. Identification of the tumour transition states occurring during EMT. Nature 556: 463-468. doi:10.1038/ s41586-018-0040-3

Pearson A, Smyth E, Babina IS, Herrera-Abreu MT, Tarazona N, Peckitt C, Kilgour E, Smith NR, Geh C, Rooney C, et al. 2016. High-level clonal FGFR amplification and response to FGFR inhibition in a translational clinical trial. Cancer Discov 6: 838-851. doi:10.1158/2159-8290.CD-15-1246

Phillips TM, McBride WH, Pajonk F. 2006. The response of CD $24^{-/ \text {low }} / \mathrm{CD} 44^{+}$breast cancer-initiating cells to radiation. I Natl Cancer Inst 98: 1777-1785. doi:10.1093/jnci/dji495

Phung B, Cieśla M, Sanna A, Guzzi N, Beneventi G, Cao Thi Ngoc P, Lauss M, Cabrita R, Cordero E, Bosch A, et al. 2019. The X-linked DDX3X RNA helicase dictates translation reprogramming and metastasis in melanoma. Cell Rep 27: 3573-3586.e7. doi:10.1016/j.celrep.2019.05.069

Pinner S, Jordan P, Sharrock K, Bazley L, Collinson L, Marais R, Bonvin E, Goding C, Sahai E. 2009. Intravital imaging reveals transient changes in pigment production and Brn2 expression during metastatic melanoma dissemination. Cancer Res 69: 7969-7977. doi:10.1158/0008-5472.CAN-09-0781

Pisco AO, Huang S. 2015. Non-genetic cancer cell plasticity and therapy-induced stemness in tumour relapse: "What does not kill me strengthens me". Br J Cancer 112: 1725-1732. doi:10.1038/bjc.2015.146

Pisco AO, Brock A, Zhou J, Moor A, Mojtahedi M, Jackson D, Huang S. 2013. Non-Darwinian dynamics in therapy-induced cancer drug resistance. Nat Commun 4: 2467. doi:10.1038/ ncomms3467

Ploper D, Taelman VF, Robert L, Perez BS, Titz B, Chen HW, Graeber TG, von Euw E, Ribas A, De Robertis EM. 2015. MITF drives endolysosomal biogenesis and potentiates Wnt signaling in melanoma cells. Proc Natl Acad Sci 112: E420E429. doi:10.1073/pnas.1424576112

Pogrebniak KL, Curtis C. 2018. Harnessing tumor evolution to circumvent resistance. Trends Genet 34: 639-651. doi:10 $.1016 /$ j.tig.2018.05.007

Polyak K, Weinberg RA. 2009. Transitions between epithelial and mesenchymal states: acquisition of malignant and stem cell traits. Nat Rev Cancer 9: 265-273. doi:10.1038/nrc2620

Potterf SB, Furumura M, Dunn KJ, Arnheiter H, Pavan WJ. 2000. Transcription factor hierarchy in Waardenburg syndrome: regulation of MITF expression by SOX10 and PAX3. Hum Genet 107: 1-6. doi:10.1007/s004390000328

Price ER, Ding H-F, Badalian T, Bhattacharya S, Takemoto C, Yao T-P, Hemesath TJ, Fisher DE. 1998. Lineage -specific signalling in melanocytes: c-Kit stimulation recruits p300/CBP to microphthalmia. I Biol Chem 273: 17983-17986. doi:10 $.1074 /$ jbc.273.29.17983

Pustylnikov S, Costabile F, Beghi S, Facciabene A. 2018. Targeting mitochondria in cancer: current concepts and immunotherapy approaches. Transl Res 202: 35-51. doi:10.1016/j.trsl .2018.07.013

Quail DF, Joyce JA. 2013. Microenvironmental regulation of tumor progression and metastasis. Nat Med 19: 1423-1437. doi:10.1038/nm.3394

Quintana E, Shackleton M, Sabel MS, Fullen DR, Johnson TM, Morrison SJ. 2008. Efficient tumour formation by single human melanoma cells. Nature 456: 593-598. doi:10.1038/ nature 07567

Quintana E, Shackleton M, Foster HR, Fullen DR, Sabel MS, Johnson TM, Morrison SJ. 2010. Phenotypic heterogeneity among tumorigenic melanoma cells from patients that is reversible and not hierarchically organized. Cancer Cell 18: 510-523. doi:10.1016/j.ccr.2010.10.012

Racle J, de Jonge K, Baumgaertner P, Speiser DE, Gfeller D. 2017. Simultaneous enumeration of cancer and immune cell types from bulk tumor gene expression data. Elife 6: e26476. doi:10.7554/eLife. 26476

Rambow F, Rogiers A, Marin-Bejar O, Aibar S, Femel J, Dewaela M, Karras P, Brown D, Chang YH, Debiec-Rychter M, et al. 2018. Towards minimal residual disease-directed therapy in melanoma. Cell 174: 843-855.e19. doi:10.1016/j.cell.2018.06 .025

Ransom RC, Carter AC, Salhotra A, Leavitt T, Marecic O, Murphy MP, Lopez ML, Wei Y, Marshall CD, Shen EZ, et al. 2018. Mechanoresponsive stem cells acquire neural crest fate in jaw regeneration. Nature 563: 514-521. doi:10.1038/ s41586-018-0650-9

Reiter F, Wienerroither S, Stark A. 2017. Combinatorial function of transcription factors and cofactors. Curr Opin Genet Dev 43: 73-81. doi:10.1016/j.gde.2016.12.007

Ribas A, Lawrence D, Atkinson V, Agarwal S, Miller WH Jr, Carlino MS, Fisher R, Long GV, Hodi FS, Tsoi J, et al. 2019. 
Combined BRAF and MEK inhibition with PD-1 blockade immunotherapy in BRAF-mutant melanoma. Nat Med 25: 936940. doi:10.1038/s41591-019-0476-5

Riesenberg S, Groetchen A, Siddaway R, Bald T, Reinhardt J, Smorra D, Kohlmeyer J, Renn M, Phung B, Aymans P, et al. 2015. MITF and c-Jun antagonism interconnects melanoma dedifferentiation with pro-inflammatory cytokine responsiveness and myeloid cell recruitment. Nat Commun 6: 8755. doi:10.1038/ncomms9755.

Rizos H, Menzies AM, Pupo GM, Carlino MS, Fung C, Hyman J, Haydu LE, Mijatov B, Becker TM, Boyd SC, et al. 2014. BRAF inhibitor resistance mechanisms in metastatic melanoma: spectrum and clinical impact. Clin Cancer Res 20: 19651977. doi:10.1158/1078-0432.CCR-13-3122

Robert C, Karaszewska B, Schachter J, Rutkowski P, Mackiewicz A, Stroiakovski D, Lichinitser M, Dummer R, Grange F, Mortier L, et al. 2015a. Improved overall survival in melanoma with combined dabrafenib and trametinib. $N$ Engl I Med 372: 30-39. doi:10.1056/NEJMoa1412690

Robert C, Long GV, Brady B, Dutriaux C, Maio M, Mortier L, Hassel JC, Rutkowski P, McNeil C, Kalinka-Warzocha E, et al. 2015b. Nivolumab in previously untreated melanoma without BRAF mutation. $N$ Engl I Med 372: 320-330. doi:10 .1056/NEJMoa1412082

Roesch A, Fukunaga-Kalabis M, Schmidt EC, Zabierowski SE, Brafford PA, Vultur A, Basu D, Gimotty P, Vogt T, Herlyn M. 2010. A temporarily distinct subpopulation of slow-cycling melanoma cells is required for continuous tumor growth. Cell 141: 583-594. doi:10.1016/j.cell.2010.04.020

Roesch A, Vultur A, Bogeski I, Wang H, Zimmermann KM, Speicher D, Körbel C, Laschke MW, Gimotty PA, Philipp $\mathrm{SE}$, et al. 2013. Overcoming intrinsic multidrug resistance in melanoma by blocking the mitochondrial respiratory chain of slow-cycling JARID1B ${ }^{\text {high }}$ cells. Cancer Cell 23: 811-825. doi:10.1016/j.ccr.2013.05.003

Rose AA, Annis MG, Frederick DT, Biondini M, Dong Z, Kwong L, Chin L, Keler T, Hawthorne T, Watson IR, et al. 2016. MAPK pathway inhibitors sensitize BRAF-mutant melanoma to an antibody-drug conjugate targeting GPNMB. Clin Cancer Res 22: 6088-6098. doi:10.1158/1078-0432.CCR-16-1192

Ruiz-Vela A, Aguilar-Gallardo C, Martínez-Arroyo AM, SorianoNavarro M, Ruiz V, Simón C. 2011. Specific unsaturated fatty acids enforce the transdifferentiation of human cancer cells toward adipocyte-like cells. Stem Cell Rev 7: 898-909. doi:10.1007/s12015-011-9253-7

Sabnis AJ, Bivona TG. 2019. Principles of resistance to targeted cancer therapy: Lessons from basic and translational cancer biology. Trends Mol Med 25: 185-197. doi:10.1016/j.molmed .2018.12.009

Sáez-Ayala M, Montenegro MF, Sánchez-Del-Campo L, Fernández-Pérez MP, Chazarra S, Freter R, Middleton M, Piñero-Madrona A, Cabezas-Herrera J, Goding CR, et al. 2013. Directed phenotype switching as an effective antimelanoma strategy. Cancer Cell 24: 105-119. doi:10.1016/j.ccr.2013.05.009

Salgia R, Kulkarni P. 2018. The genetic/non-genetic duality of drug "Resistance" in cancer. Trends Cancer 4: 110-118. doi:10.1016/j.trecan.2018.01.001

Sato S, Roberts K, Gambino G, Cook A, Kouzarides T, Goding CR. 1997. CBP/p300 as a co-factor for the Microphthalmia transcription factor. Oncogene 14: 3083-3092. doi:10.1038/sj .onc. 1201298

Schacht T, Oswald M, Eils R, Eichmüller SB, König R. 2014. Estimating the activity of transcription factors by the effect on their target genes. Bioinformatics 30: i401-407. doi:10.1093/ bioinformatics/btu446
Schatton T, Murphy GF, Frank NY, Yamaura K, Waaga-Gasser AM, Gasser M, Zhan Q, Jordan S, Duncan LM, Weishaupt $\mathrm{C}$, et al. 2008. Identification of cells initiating human melanomas. Nature 451: 345-349. doi:10.1038/nature06489

Schepsky A, Bruser K, Gunnarsson GJ, Goodall J, Hallsson JH, Goding CR, Steingrimsson E, Hecht A. 2006. The microphthalmia-associated transcription factor Mitf interacts with $\beta$-catenin to determine target gene expression. Mol Cell Biol 26: 8914-8927. doi:10.1128/MCB.02299-05

Schwarz RF, Ng CK, Cooke SL, Newman S, Temple J, Piskorz AM, Gale D, Sayal K, Murtaza M, Baldwin PJ, et al. 2015. Spatial and temporal heterogeneity in high-grade serous ovarian cancer: a phylogenetic analysis. PLoS Med 12: e1001789. doi:10.1371/journal.pmed.1001789

Scott AM, Wolchok JD, Old LJ. 2012. Antibody therapy of cancer. Nat Rev Cancer 12: 278-287. doi:10.1038/nrc3236

Seftor RE, Hess AR, Seftor EA, Kirschmann DA, Hardy KM, Margaryan NV, Hendrix MJ. 2012. Tumor cell vasculogenic mimicry: from controversy to therapeutic promise. Am J Pathol 181: 1115-1125. doi:10.1016/j.ajpath.2012.07.013

Seguin L, Desgrosellier JS, Weis SM, Cheresh DA. 2015. Integrins and cancer: regulators of cancer stemness, metastasis, and drug resistance. Trends Cell Biol 25: 234-240. doi:10.1016/j .tcb.2014.12.006

Shaffer SM, Dunagin MC, Torborg SR, Torre EA, Emert B, Krepler C, Beqiri M, Sproesser K, Brafford PA, Xiao M, et al. 2017. Rare cell variability and drug-induced reprogramming as a mode of cancer drug resistance. Nature 546: 431-435. doi:10.1038/ nature22794

Shain AH, Bastian BC. 2016. From melanocytes to melanomas. Nat Rev Cancer 16: 345-358. doi:10.1038/nrc.2016.37

Sharma SV, Lee DY, Li B, Quinlan MP, Takahashi F, Maheswaran S, McDermott U, Azizian N, Zou L, Fischbach MA, et al. 2010. A chromatin-mediated reversible drug-tolerant state in cancer cell subpopulations. Cell 141: 69-80. doi:10.1016/j .cell.2010.02.027

Shi H, Hong A, Kong X, Koya RC, Song C, Moriceau G, Hugo W, Yu CC, Ng C, Chodon T, et al. 2014. A novel AKT1 mutant amplifies an adaptive melanoma response to BRAF inhibition. Cancer Discov 4: 69-79. doi:10.1158/2159-8290.CD-13-0279

Singh A, Settleman J. 2010. EMT, cancer stem cells and drug resistance: an emerging axis of evil in the war on cancer. Oncogene 29: 4741-4751. doi:10.1038/onc.2010.215

Smith MP, Brunton H, Rowling EJ, Ferguson J, Arozarena I, Miskolczi Z, Lee JL, Girotti MR, Marais R, Levesque MP, et al. 2016. Inhibiting drivers of non-mutational drug tolerance is a salvage strategy for targeted melanoma therapy. Cancer Cell 29: 270-284. doi:10.1016/j.ccell.2016.02.003

Smith MP, Rowling EJ, Miskolczi Z, Ferguson J, Spoerri L, Haass NK, Sloss O, McEntegart S, Arozarena I, von Kriegsheim A, et al. 2017. Targeting endothelin receptor signalling overcomes heterogeneity driven therapy failure. EMBO Mol Med 9: 1011-1029. doi:10.15252/emmm.201607156

Somasundaram R, Villanueva J, Herlyn M. 2012. Intratumoral heterogeneity as a therapy resistance mechanism: role of melanoma subpopulations. Adv Pharmacol 65: 335-359. doi:10 .1016/B978-0-12-397927-8.00011-7

Sosa MSS, Bragado P, Aguirre-Ghiso JA. 2014. Mechanisms of disseminated cancer cell dormancy: an awakening field. Nat Rev Cancer 14: 611-622. doi:10.1038/nrc3793

Sottoriva A, Spiteri I, Piccirillo SG, Touloumis A, Collins VP, Marioni JC, Curtis C, Watts C, Tavare S. 2013. Intratumor heterogeneity in human glioblastoma reflects cancer evolutionary dynamics. Proc Natl Acad Sci 110: 4009-4014. doi:10 $.1073 /$ pnas. 1219747110 
Spagnolo F, Ghiorzo P, Queirolo P. 2014. Overcoming resistance to BRAF inhibition in BRAF-mutated metastatic melanoma. Oncotarget 5: 10206-10221. doi:10.18632/oncotarget.2602

Straussman R, Morikawa T, Shee K, Barzily-Rokni M, Qian ZR, Du J, Davis A, Mongare MM, Gould J, Frederick DT, et al. 2012. Tumour micro-environment elicits innate resistance to RAF inhibitors through HGF secretion. Nature 487: 500504. doi:10.1038/nature 11183

Strub T, Giuliano S, Ye T, Bonet C, Keime C, Kobi D, Le Gras S, Cormont M, Ballotti R, Bertolotto C, et al. 2011. Essential role of microphthalmia transcription factor for DNA replication, mitosis and genomic stability in melanoma. Oncogene 30: 2319-2332. doi:10.1038/onc.2010.612

Su Y, Wei W, Robert L, Xue M, Tsoi J, Garcia-Diaz A, Homet Moreno B, Kim J, Ng RH, Lee JW, et al. 2017. Single-cell analysis resolves the cell state transition and signaling dynamics associated with melanoma drug-induced resistance. Proc Natl Acad Sci 114: 13679-13684. doi:10.1073/pnas.1712064115

Suzuki T, Osumi N, Wakamatsu Y. 2010. Stabilization of ATF4 protein is required for the regulation of epithelial-mesenchymal transition of the avian neural crest. Dev Biol 344: 658668. doi:10.1016/j.ydbio.2010.05.492

Thurber AE, Douglas G, Sturm EC, Zabierowski SE, Smit DJ, Ramakrishnan SN, Hacker E, Leonard JH, Herlyn M, Sturm RA. 2011. Inverse expression states of the BRN2 and MITF transcription factors in melanoma spheres and tumour xenografts regulate the NOTCH pathway. Oncogene 30: 3036-3048. doi:10.1038/onc.2011.33

Tirosh I, Izar B, Prakadan SM, Wadsworth MH, Treacy D, Trombetta JJ, Rotem A, Rodman C, Lian C, Murphy G, et al. 2016. Dissecting the multicellular ecosystem of metastatic melanoma by single-cell RNA-seq. Science 352: 189-196. doi:10 $.1126 /$ science.aad0501

Titz B, Lomova A, Le A, Hugo W, Kong X, Ten Hoeve J, Friedman M, Shi H, Moriceau G, Song C, et al. 2016. JUN dependency in distinct early and late BRAF inhibition adaptation states of melanoma. Cell Discov 2: 16028. doi:10.1038/celldisc.2016 .28

Torre E, Dueck H, Shaffer S, Gospocic J, Gupte R, Bonasio R, Kim J, Murray J, Raj A. 2018. Rare cell detection by single-cell RNA sequencing as guided by single-molecule RNA FISH. Cell Syst 6: 171-179.e5. doi:10.1016/j.cels.2018.01.014

Tsai JH, Donaher JL, Murphy DA, Chau S, Yang J. 2012. Spatiotemporal regulation of epithelial-mesenchymal transition is essential for squamous cell carcinoma metastasis. Cancer Cell 22: 725-736. doi:10.1016/j.ccr.2012.09.022

Tsoi J, Robert L, Paraiso K, Galvan C, Sheu KM, Lay J, Wong DJL, Atefi M, Shirazi R, Wang X, et al. 2018. Multi-stage differentiation defines melanoma subtypes with differential vulnerability to drug-induced iron-dependent oxidative stress. Cancer Cell 33: 890-904.e5. doi:10.1016/j.ccell.2018.03.017

Tuncer E, Calcada RR, Zingg D, Varum S, Cheng P, Freiberger SN, Deng CX, Kleiter I, Levesque MP, Dummer R, et al. 2019. SMAD signaling promotes melanoma metastasis independently of phenotype switching. J Clin Invest 129: 2702-2716.

Turajlic S, Sottoriva A, Graham T, Swanton C. 2019. Resolving genetic heterogeneity in cancer. Nat Rev Genet 20: 404-416. doi:10.1038/s41576-019-0114-6

van der Knaap JA, Verrijzer CP. 2016. Undercover: gene control by metabolites and metabolic enzymes. Genes Dev 30: 23452369. doi:10.1101/gad.289140.116

Vanharanta S, Massagué J. 2013. Origins of metastatic traits. Cancer Cell 24: 410-421. doi:10.1016/j.ccr.2013.09.007

Van Raamsdonk CD, Bezrookove V, Green G, Bauer J, Gaugler L, O'Brien JM, Simpson EM, Barsh GS, Bastian BC. 2009. Fre- quent somatic mutations of GNAQ in uveal melanoma and blue naevi. Nature 457: 599-602. doi:10.1038/nature07586

Van Raamsdonk CD, Griewank KG, Crosby MB, Garrido MC, Vemula S, Wiesner T, Obenauf AC, Wackernagel W, Green $\mathrm{G}$, Bouvier $\mathrm{N}$, et al. 2010. Mutations in GNA11 in uveal melanoma. $N$ Engl I Med 363: 2191-2199. doi:10.1056/ NEJMoa1000584

Vazquez F, Lim JH, Chim H, Bhalla K, Girnun G, Pierce K, Clish CB, Granter SR, Widlund HR, Spiegelman BM, et al. 2013. PGC1 $\alpha$ expression defines a subset of human melanoma tumors with increased mitochondrial capacity and resistance to oxidative stress. Cancer Cell 23: 287-301. doi:10.1016/j .ccr.2012.11.020

Verastegui C, Bille K, Ortonne JP, Ballotti R. 2000. Regulation of the microphthalmia-associated transcription factor gene by the waardenburg syndrome type 4 gene, SOX10. I Biol Chem 275: 30757-30760. doi:10.1074/jbc.C000445200

Verfaillie A, Imrichova H, Atak ZK, Dewaele M, Rambow F, Hulselmans G, Christiaens V, Svetlichnyy D, Luciani F, Van den Mooter L, et al. 2015. Decoding the regulatory landscape of melanoma reveals TEADS as regulators of the invasive cell state. Nat Commun 6: 6683. doi:10.1038/ncomms7683

Vlamakis H, Aguilar C, Losick R, Kolter R. 2008. Control of cell fate by the formation of an architecturally complex bacterial community. Genes Dev 22: 945-953. doi:10.1101/gad .1645008

Vlamakis H, Chai Y, Beauregard P, Losick R, Kolter R. 2013. Sticking together: building a biofilm the Bacillus subtilis way. Nat Rev Microbiol 11: 157-168. doi:10.1038/ nrmicro2960

Vogelstein B, Papadopoulos N, Velculescu VE, Zhou S, Diaz LA, Kinzler KW. 2013. Cancer genome landscapes. Science 339: 1546-1558. doi:10.1126/science. 1235122

Wang Z, Cao S, Morris JS, Ahn J, Liu R, Tyekucheva S, Gao F, Li B, Lu W, Tang X, et al. 2018. Transcriptome deconvolution of heterogeneous tumor samples with immune infiltration. iScience 9: 451-460. doi:10.1016/j.isci.2018.10.028

Westermarck J. 2010. Regulation of transcription factor function by targeted protein degradation: an overview focusing on $\mathrm{p} 53$, c-Myc, and c-Jun. Methods Mol Biol 647: 31-36. doi:10.1007/ 978-1-60761-738-9_2

Widlund HR, Horstmann MA, Price ER, Cui J, Lessnick SL, Wu M, He X, Fisher DE. 2002. $\beta$-catenin-induced melanoma growth requires the downstream target Microphthalmia-associated transcription factor. J Cell Biol 158: 1079-1087. doi:10 $.1083 /$ jcb.200202049

Wilson RE, Dooley TP, Hart IR. 1989. Induction of tumorigenicity and lack of in vitro growth requirement for 12-O-tetradecanoylphorbol-13-acetate by transfection of murine melanocytes with v-Ha-ras. Cancer Res 49: 711-716.

Wolchok JD, Chiarion-Sileni V, Gonzalez R, Rutkowski P, Grob JJ, Cowey CL, Lao CD, Wagstaff J, Schadendorf D, Ferrucci PF, et al. 2017. Overall survival with combined Nivolumab and Ipilimumab in advanced melanoma. N Engl J Med 377: 1345-1356. doi:10.1056/NEJMoa1709684

Woodward WA, Chen MS, Behbod F, Alfaro MP, Buchholz TA, Rosen JM. 2007. WNT/ $\beta$-catenin mediates radiation resistance of mouse mammary progenitor cells. Proc Nat1 Acad Sci 104: 618-623. doi:10.1073/pnas.0606599104

Wouters J, Kalender-Atak Z, Minnoye L, Spanier KI, De Wegeneer M, González-Blas CB, MAuduit D, Davie K, Hulselmans G, Najem A, et al. 2019. Single-cell gene regulatory network analysis reveals new melanoma cell states and transition trajectories during phenotype switching. bioRxiv. doi:10.1101/715995 
Wu M, Hemesath TJ, Takemoto CM, Horstmann MA, Wells AG, Price ER, Fisher DZ, Fisher DE. 2000. c-Kit triggers dual phosphorylations, which couple activation and degradation of the essential melanocyte factor Mi. Genes Dev 14: 301-312.

Xu W, Gong L, Haddad MM, Bischof O, Campisi J, Yeh ET, Medrano EE. 2000. Regulation of microphthalmia-associated transcription factor MITF protein levels by association with the ubiquitin-conjugating enzyme hUBC9. Exp Cell Res 255: 135-143. doi:10.1006/excr.2000.4803

Xue Z, Yan H, Li J, Liang S, Cai X, Chen X, Wu Q, Gao L, Wu K, Nie $Y$, et al. 2012. Identification of cancer stem cells in vincristine preconditioned SGC7901 gastric cancer cell line. J Cell Biochem 113: 302-312. doi:10.1002/jcb.23356

Yachida S, Jones S, Bozic I, Antal T, Leary R, Fu B, Kamiyama M, Hruban RH, Eshleman JR, Nowak MA, et al. 2010. Distant metastasis occurs late during the genetic evolution of pancreatic cancer. Nature 467: 1114-1117. doi:10.1038/nature09515

Yavuzer U, Keenan E, Lowings P, Vachtenheim J, Currie G, Goding CR. 1995. The Microphthalmia gene product interacts with the retinoblastoma protein in vitro and is a target for deregulation of melanocyte- specific transcription. Oncogene 10: $123-134$.
Yin C, Zhu B, Zhang T, Liu T, Chen S, Liu Y, Li X, Miao X, Li S, Mi $X$, et al. 2019. Pharmacological targeting of STK19 inhibits oncogenic NRAS-driven melanomagenesis. Cell 176: 11131127.e16. doi:10.1016/j.cell.2019.01.002

Zhang J, Fuijimoto J, Zhang J, Wedge DC, Song X, Zhang J, Seth S, Chow CW, Cao Y, Gumbs C, et al. 2014. Intratumor heterogeneity in localized lung adenocarcinomas delineated by multiregion sequencing. Science 346: 256-259. doi:10.1126/science .1256930

Zhang D, Wang Y, Shi Z, Liu J, Sun P, Hou X, Zhang J, Zhao S, Zhou BP, Mi J. 2015a. Metabolic reprogramming of cancer-associated fibroblasts by IDH3 $\alpha$ downregulation. Cell Rep 10: 1335-1348. doi:10.1016/j.celrep.2015.02.006

Zhang T, Zhou Q, Ogmundsdottir MH, Moller K, Siddaway R, Larue L, Hsing M, Kong SW, Goding CR, Palsson A, et al. 2015b. Mitf is a master regulator of the v-ATPase, forming a control module for cellular homeostasis with v-ATPase and TORC1. J Cell Sci 128: 2938-2950. doi:10.1242/jcs.173807

Zhang G, Frederick DT, Wu L, Wei Z, Krepler C, Srinivasan S, Chae YC, Xu X, Choi H, Dimwamwa E, et al. 2016. Targeting mitochondrial biogenesis to overcome drug resistance to MAPK inhibitors. J Clin Invest 126: 1834-1856. doi:10.1172/ JCI82661 


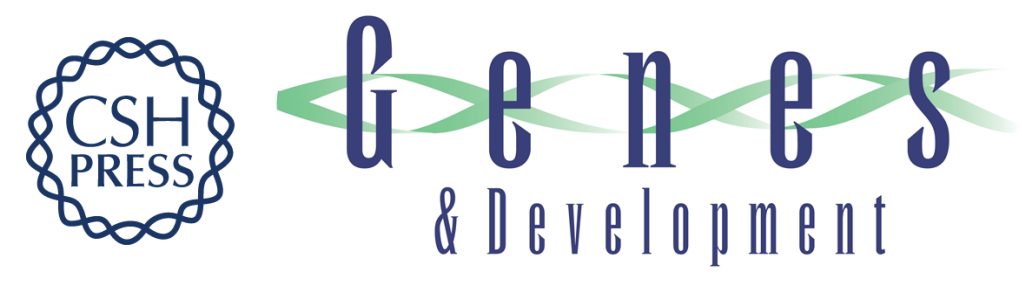

\section{Melanoma plasticity and phenotypic diversity: therapeutic barriers and opportunities}

Florian Rambow, Jean-Christophe Marine and Colin R. Goding

Genes Dev. 2019, 33:

Access the most recent version at doi:10.1101/gad.329771.119

\begin{tabular}{|c|c|}
\hline References & $\begin{array}{l}\text { This article cites } 230 \text { articles, } 57 \text { of which can be accessed free at: } \\
\text { http://genesdev.cshlp.org/content/33/19-20/1295.full.html\#ref-list-1 }\end{array}$ \\
\hline $\begin{array}{r}\text { Creative } \\
\text { Commons } \\
\text { License }\end{array}$ & $\begin{array}{l}\text { This article is distributed exclusively by Cold Spring Harbor Laboratory Press for the first } \\
\text { six months after the full-issue publication date (see } \\
\text { http://genesdev.cshlp.org/site/misc/terms.xhtml). After six months, it is available under a } \\
\text { Creative Commons License (Attribution-NonCommercial } 4.0 \text { International), as described } \\
\text { at http://creativecommons.org/licenses/by-nc/4.0/. }\end{array}$ \\
\hline $\begin{array}{l}\text { Email Alerting } \\
\text { Service }\end{array}$ & $\begin{array}{l}\text { Receive free email alerts when new articles cite this article - sign up in the box at the top } \\
\text { right corner of the article or click here. }\end{array}$ \\
\hline
\end{tabular}

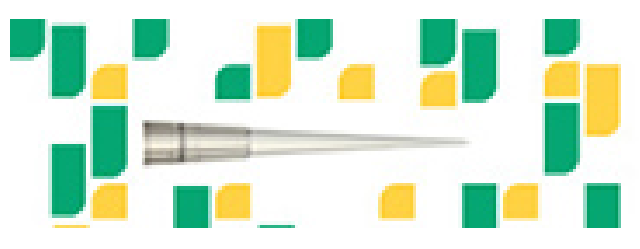

Focused on your science. 